\title{
El proyecto de Ley de Transparencia y acceso a la información pública y el margen de actuación de las Comunidades Autónomas
}

\author{
Emilio Guichot \\ Profesor Titular de Derecho Administrativo \\ Universidad de Sevilla
}

SUMARIO: I.- EL PROYECTO DE LEY DE TRANSPARENCIA, ACGESO A LA INFORMACIÓN PÚBLICA Y BUEN GOBIERNO. II.- EL SENTIDO DE LA TRANSPARENCIA Y EL ESTADO DE LA CUESTIÓN EN EL DERECHO COMPARADO. III.LA SITUACIÓN ACTUAL EN ESPAÑA Y LA "TORMENTA PERFEGTA" QUE HA IMPULSADO FINALMENTE UNA CARRERA POR LA TRANSPARENCIA. IV.- ANÁLISIS DEL PROYECTO DE LEY: LUCES Y SOMBRAS. MATERIALES PARA UN DEBATE. 1. Ámbito objetivo de aplicación. El entronque con la normativa sobre acceso a los archivos y sus aporías. 2. La naturaleza del derecho, la base competencial y los sujetos obligados. 3. La publicidad activa. 4. El objeto del derecho de acceso. 5. El titular del derecho. 6. Limitaciones. 7. En particular, las relaciones entre transparencia y acceso a la información y protección de datos personales. 8 . Procedimiento y organización. 9. Garantías. 10.- Coda: el margen de actuación de las Comunidades Autónomas

\section{RESUMEN}

El artículo analiza el actual proyecto de Ley de Transparencia y Acceso a la información desde un punto de vista crítico y propositivo. Asimismo, estudia cuál es el margen de actuación que deja al legislador autonómico, referido fundamentalmente a la ampliación de la publicidad activa, a las disposiciones en materia de organización y a la configuración de una autoridad independiente de control.

Palabras clave: Transparencia, acceso a la información, comunidades autónomas 


\section{ABSTRACT}

The article analyzes the current draft law on transparency and access to information from a critical point of view and offers different proposals. It also examines the margin of decision for the regional legislature, referred to the extension of pro-active disclosure, internal organization and the establishment of an independent supervisory authority

Key words: Transparency, access to information, regions

\section{EL PROYEGTO DE LEY DE TRANSPARENCIA, ACGESO A LA INFORMACIÓN PÚBLICA Y BUEN GOBIERNO}

El Gobierno aprobó el 23 de marzo de 2012 un primer Anteproyecto de Ley de Transparencia, Acceso a la Información Pública y Buen Gobierno ${ }^{1}$, y el 18 de mayo, un segundo Anteproyecto, tras someter el primero a un procedimiento de consulta pública entre los días 26 de marzo y 10 de abril ${ }^{2}$. Entre uno y otro texto se introdujeron ligeras modificaciones como resultado de la propia iniciativa gubernamental, de algunas sugerencias recibidas a través del procedimiento de consulta pública, y por otras vías de debate e influencia, desde artículos de prensa hasta jornadas de estudio, conferencias, etc., que se han ido organizando en número considerable en este período, y que dan cuenta de la importancia que las Administraciones, los centros de estudio e investigación, los académicos y, en fin, la sociedad, dan a este proyecto. $\mathrm{Al}$ respecto, hay que hacer especial referencia a la promoción por parte del Gobierno de un Grupo de expertos en la materia, entre los cuales tengo el honor de encontrarme, en el seno del Centro de Estudios Políticos y Constitucionales, para su estudio y la

\footnotetext{
${ }^{1}$ http://www.leydetransparencia.gob.es/anteproyecto/index.htm

${ }^{2}$ Se formularon críticas desde diversos sectores a la no publicación de las sugerencias y opiniones de los ciudadanos. Posteriormente, el primer partido de la oposición, el PSOE, pidió acceso a las aportaciones ciudadanas antes de presentar las enmiendas. El Gobierno le remitió un denominado "Informe sobre la consulta pública electrónica del Anteproyecto de Ley de Transparencia, Acceso a la Información Pública y Buen Gobierno (puede consultarse en: http://www.access-info.org/documents/1054827 16-Informe-del-Ministerio-de-Presidencia.pdf). En él se informa de que la página web:

www.leydetransparencia.gob.es tuvo un total de 78.107 visitas y se recibieron un total de 3.669 observaciones a través de ella y otras 14 por registro. El perfil de los participantes en la consulta fue diverso: junto a ciudadanos individuales participaron Administraciones Públicas, asociaciones profesionales, organizaciones activas en materia de transparencia y otros colectivos. Requerido acceso a los originales, la Secretaría de Estado de Relaciones con las Cortes sugirió que la consulta se hiciera in situ, por el supuesto riesgo a una vulneración del derecho a la protección de datos que podría generar de lo contrario su remisión.
} 
formulación de propuestas (entre los que tuve el honor de encontrarme), que, sin embargo, no llegó a ser reunido de forma conclusiva para formular propuestas o trasladar valoraciones antes del envío del Proyecto al Congreso de los Diputados. El Anteproyecto fue informado por la Agencia Española de Protección de Datos y por el Consejo de Estado (se trataba en este caso de un informe facultativo), si bien los informes permanecieron también sin publicidad oficial $^{3}$. Asimismo, se han iniciado una serie de comparecencias de expertos ante la Comisión Constitucional del Congreso de los Diputados entre los que he tenido el privilegio de ser incluido.

Se trata de una iniciativa cuya importancia política y jurídica es difícil exagerar. Evidentemente, una Ley como ésta no cambia por sí sola una sociedad, si no va acompañada de una mejora en la ética pública (de gobernantes y gobernados) o, al menos, de garantías efectivas de su cumplimiento y de una voluntad ciudadana de conocimiento, participación y control. Pero, sin duda, una Ley de Transparencia es la ley más importante que puede aprobarse para lograr una mejor gestión, una mayor participación y, por ende, un menor grado de corrupción. Como le escuché recientemente al Presidente de la Comisión para la Transparencia de Chile, una buena gestión del propio cuerpo conduciría a llevar siempre una vida sana, pero no es casual que sea en primavera cuando se llenan los gimnasios, y en otoño cuando se despueblan: el sometimiento a la mirada ajena tiene claros efectos motivadores. $\mathrm{O}$, en la frase clásica del Juez BRANDEIS, "se dice que la luz del sol es el mejor de los desinfectantes" 4 .

\footnotetext{
${ }^{3}$ Puede encontrarse una denuncia de este hecho en: http://www.eldiario.es/zonacritica/informesocultos-Ley-Transparencia_6_45905413.html con enlaces al informe de la Agencia Española de Protección de Datos en http://es.scribd.com/doc/105484598/Informe-de-la-Agencia-de-Proteccion-de-Datos y al del Consejo de Estado en http://es.scribd.com/doc/105482040/Informe-del-Consejo-Estado-sobrela-Ley-de-Transparencia. Este último informe, por cierto, consideró que habida cuenta el contenido del Anteproyecto, se debió haber evacuado consulta al Consejo General del Poder Judicial, a la Fiscalía General del Estado y al Ministerio de Defensa y dado audiencia a las Comunidades Autónomas y recabado el parecer del Centro de Estudios Políticos y Constitucionales, en cuyo seno se había constituido un Comité de Expertos al que el Ministerio de la Presidencia encargó la elaboración de un informe sobre el anteproyecto que finalmente no fue evacuado y que hubiera aportado importantes elementos de juicio. Además, echó en falta la emisión de algún documento en el que resumiesen las observaciones formuladas por los distintos órganos, entidades y sujetos que intervinieron en la tramitación y se explicasen las razones por las que muchas de sus sugerencias no fueron atendidas. Finalmente, como se ha expuesto en la nota anterior, se hizo público un informe resumen de observaciones.

${ }^{4}$ Académicamente, por cierto, basta acudir a cualquier Manual de Derecho Administrativo, en especial anglosajón o escandinavo, para ver la importancia capital que para el Derecho público tiene esta materia y su peso cuantitativo en la disciplina.
} 


\section{EL SENTIDO DE LA TRANSPARENGIA Y EL ESTADO DE LA GUESTIÓN EN EL DEREGHO COMPARADO ${ }^{5}$}

La necesidad de transparencia de las actuaciones públicas se ha ido convirtiendo en una exigencia cada vez más insistente por parte de actores cualificados: estudiosos, periodistas, organizaciones no gubernamentales, etc. En las sociedades complejas de fines del segundo milenio y comienzos del tercero se ha ido generalizando la idea de que una sociedad democrática requiere que los ciudadanos, por sí mismos y a través de los medios de comunicación social, puedan conocer con la mayor amplitud cómo actúan los poderes públicos y, de ese modo, controlarlos, detectar los malos funcionamientos y mejorar así la calidad de la gestión pública. Se trata, además, de un tema que parece estar al margen de las diferentes ideologías políticas o mejor dicho, ser previo a ellas, en la medida en que conecta con la base misma que permite su expresión, esto es, con la democracia.

Los países pioneros en el reconocimiento y regulación del derecho de acceso a la información pública se encuentran entre los más desarrollados del mundo desde una perspectiva democrática. El movimiento fue liderado por los países escandinavos y por Estados Unidos y los países de su área de influencia anglófona. Entre finales de los setenta y principios de los noventa, se expandió entre los países latinos de la Europa occidental. A finales de los noventa y principios del siglo XXI hubo una auténtica eclosión y se generalizó la aprobación de leyes de transparencia y acceso a la información pública en los países de Europa occidental que aún carecían de ella, entre ellos, Reino Unido y Alemania; en los países de Europa y de Asia que se encontraban en la órbita o integrados en la Unión Soviética hasta la caída del muro de Berlín, incluida recientemente la propia Rusia, y en las restantes zonas de América Central y del Sur, Asia, África y Oceanía. A todas estas regulaciones nacionales, que se acercan al centenar, se le suman más del doble de normas subnacionales y la regulación de acceso a la información en poder de la Unión Europea y un instrumento regional europeo de especial importancia que ha estado muy presente en la redacción del Proyecto, el Convenio núm. 205 del Consejo de Europa sobre acceso a los documentos públicos, abierto a la firma de los Estados el 18 de junio

\footnotetext{
${ }^{5}$ Permítase la remisión a mis trabajos Transparencia y acceso a la información en el Derecho europeo, Global Law Press/Editorial Derecho Global, 2011, y "Derecho de acceso a la información: experiencias regionales y estatales en Europa y América”, Derecho Comparado de la Información, enero-junio 2012, pp. 135-188, y la bibliografía en ellos citada.
} 
de 2009, que establece un mínimo estándar europeo ${ }^{6}$. Puede decirse, pues, que se ha generalizado a nivel mundial la existencia de leyes de transparencia y acceso a la información. Los países política, social y económicamente más desarrollados actuaron como pioneros, pero, en la actualidad, países de todos los continentes se han sumado a este movimiento, con leyes en muchos casos más completas y actualizadas debido precisamente a su fecha de aprobación, mientras que en los países pioneros la inmensa mayoría de las leyes originales se han ido modificando, muy en especial para adaptarse a nuevas realidades, como la reutilización de la información pública y la aparición de las nuevas tecnologías de la información.

La expansión de este género de normas en los últimos años ha ido, en definitiva, asociada a la generalización de la democracia representativa. No obstante, en la mayoría de las ocasiones, ha debido concurrir una labor activa de las organizaciones no gubernamentales dedicadas a la promoción de la transparencia; de las asociaciones de periodistas y de los medios de comunicación y, en un grado difícil de discernir, de la doctrina académica. Ni siquiera esos factores han sido siempre suficientes, pues se ha necesitado, las más de las veces, un impulso político nacido en contextos de crisis de legitimación democrática, sospechas de corrupción y debilidad gubernamental -el caso de Estados Unidos, y la "reactivación" de la Ley tras la crisis del Watergate, o de la Unión Europea, y la aprobación del Reglamento 1049/2001 como respuestas a una opinión pública especialmente crítica en relación con el oscurantismo, la corrupción y el déficit democrático de las instituciones son ilustrativos- o de nacimiento de nuevas democracias o de apertura gradual de regímenes opacos -véase la cronología de su expansión en Latinoamérica o Europa del Este o el resto del mundo. En definitiva, pese a que los análisis políticos y económicos muestran a las claras las virtudes de la transparencia, la historia muestra que en la mayoría de los países a la transparencia "se llega" frente a una reticencia inicial del que ejerce el poder y de las burocracias a someter su gestión a los focos del debate público informado. En todo caso, el resultado final de este proceso y de esta conjunción de factores ha sido la aceptación generalizada de la necesidad y la conveniencia de aprobar normas que garanticen y regulen el acceso a la información pública.

\footnotetext{
${ }^{6}$ La Exposición de Motivos del Anteproyecto afirma al respecto, aun sin nombrarlo, que éste "constituye un paso fundamental y necesario que se verá acompañado en el futuro con el impulso y adhesión por parte del Estado tanto a iniciativas multilaterales en este ámbito como con la firma de los instrumentos internacionales ya existentes en esta materia."
} 


\section{LA SITUAGIÓN AGTUAL EN ESPAÑA Y LA "TORMENTA PERFECTA" QUE HA IMPULSADO FINALMENTE UNA CA- RRERA POR LA TRANSPARENCIA}

A día de hoy, el derecho de acceso a la información pública está contemplado en el artículo 105.c) de la Constitución y desarrollado con carácter general en el artículo 37 de la Ley 30/1992, de 26 de noviembre, de Régimen Jurídico de las Administraciones Públicas y del Procedimiento Administrativo Común, cuyas deficiencias y lagunas (incluida la falta de regulación del procedimiento y de previsión de un órgano independiente de control) son ostensibles. No es de extrañar, en consecuencia, que esta regulación, defectuosa e introducida sin autonomía en una norma "burocrática", haya pasado desapercibida y haya sido incapaz de generar una cultura de la transparencia, ni en los ciudadanos ni en la Administración. Falta, pues, una regulación básica y general digna de ese nombre como existe en todos los países homologables de nuestro entorno ${ }^{7}$.

$\mathrm{Al}$ igual que ocurriera en otros países, también en España han tenido que ser los impulsos de la sociedad en tiempos de una profunda crisis de confianza política, institucional y económica los que han colocado la transparencia en la agenda política de forma no sólo nominal sino efectiva. Se ha producido, en efecto, lo que podríamos calificar como la "tormenta perfecta de la transparencia”. Desde hace años, y en especial en los últimos tiempos, editoriales y artículos en medios de comunicación, de muy diferente signo, académicos y asociaciones y organizaciones no gubernamentales venían reclamando la necesidad de aprobar una Ley de acceso a la información. Esta demanda social comenzó a calar en algunos programas electorales, como ocurrió en el del PSOE para las elecciones generales de 2004 y 2008. Mediante la resolución número 33 aprobada tras el Debate sobre el Estado de la Nación de 2010, "sobre el derecho de libre acceso a la información pública", el Congreso de los Diputados instó al Gobierno a presentar en el plazo máximo de un año un Proyecto de Ley, en el que de hecho, estaba trabajando, prueba de lo cual es que el lunes 16 de agosto de 2010 era portada del periódico generalista de mayor tirada en

\footnotetext{
${ }^{7}$ Junto con esta regulación, hay que mencionar la Ley 27/2006, de 18 de julio, por la que se regulan los derechos de acceso a la información, de participación pública y de acceso a la justicia en materia de medio ambiente y la Ley $37 / 2007$, de 16 de noviembre, sobre reutilización de la información del sector público, aprobadas al calor de la necesidad de transponer sendas directivas comunitarias, así como normas sectoriales en materia de contratos, subvenciones, empleados públicos, e incluso sanciones administrativas que prevén diferentes supuestos de publicidad.
} 
España, con gran despliegue en páginas interiores dando detallada cuenta de su contenido, la inminente (en el Consejo de Ministros de ese mismo viernes) aprobación de un Anteproyecto de Ley de Transparencia y Acceso a la Información ${ }^{8}$, y en la página web de una organización no gubernamental dedicada a la transparencia se filtró el propio texto del llamado Anteproyecto ${ }^{9}$; dicho Anteproyecto, sin embargo, no llegó a aprobarse. El asunto pareció desaparecer de la agenda del Gobierno. Se trató, desde luego, de una desaparición expresiva del divorcio entre los políticos y la ciudadanía y de la importancia del compromiso y la acción de ésta para impulsar la actividad de aquéllos. En efecto, poco más tarde se hacía omnipresente el llamado movimiento 15-M, "Democracia Real Ya", que abanderó como una de sus reivindicaciones más señeras la necesidad de aprobación de una Ley de Transparencia. Siempre a rastras, sea de la Unión Europea sea de su propia ciudadanía, los políticos españoles se hicieron eco por fin de este clamor y la transparencia pasó a ocupar un primer plano en la agenda política, hasta el punto de pasarse de la desidia a la carrera por la transparencia. En efecto, el 7 de abril de 2011, UPyD presentaba en el Congreso una proposición de Ley orgánica de principios y medidas contra la corrupción y por la transparencia en la gestión pública ${ }^{10}$; el 20 de junio de 2011, el Congreso de los Diputados aprobó por unanimidad una moción por la que instaba al Gobierno a presentar un Proyecto de Ley de Transparencia, no ya en un año, sino en unas semanas, antes de agosto de ese mismo año, el 29 de junio, el PP presentaba en el Congreso una proposición de ley de Transparencia, Acceso a la Información Pública y Buen Gobierno ${ }^{11}$, y el 29 de julio de 2011 el Gobierno aprobaba el Anteproyecto de Ley -a la vez que se hacía público el adelanto electoral-. Iniciativas, todas ellas, pues, cara a la galería, habida cuenta el momento en que se presentaron. En los programas electorales de casi todos los grupos políticos para las elecciones de 20 de noviembre de 2011 figuraba ya la promesa de aprobación de una Ley de Transparencia. Recién inaugurada la actual legislatura, el PSOE presentó en el Congreso el 13 de diciembre de 2011 una proposición de ley sobre la base del Anteproyecto del anterior Gobierno ${ }^{12}$ y UPyD lo hizo el 22 de diciembre, reproduciendo su proposición de la anterior legislatura. Finalmente, el Gobierno aprobó el 23 de marzo de 2012 su propio Anteproyecto, muy cambiado res-

\footnotetext{
8 http://www.elpais.com/articulo/espana/ley/regulara/derecho/saber/ciudadanos/Administracion/elpepuesp/20100816elpepinac_1/Tes

${ }^{9}$ http:// www.access-info.org/documents/Access_Docs/Advancing/Spain/Espana_Anteproyecto_Ley_Transparencia.pdf

${ }^{10} \mathrm{http}: / /$ www.congreso.es/public_oficiales/L9/CONG/BOCG/B/B_314-01.PDF\#page=1

${ }^{11} \mathrm{http}$ // /www.congreso.es/public_oficiales/L9/CONG/BOCG/B/B_326-01.PDF\#page=1

12 http://www.congreso.es/public_oficiales/L10/CONG/BOCG/B/B_010-01.PDF\#page=1
} 
pecto de la anterior proposición de ley del $\mathrm{PP}^{13}$ y con no pocos elementos parcialmente comunes a los textos impulsados por el anterior Gobierno. En definitiva, si bien este paso de la inmovilidad al sprint tiene algo de sonrojante, mirado en positivo, es un buen ejemplo de cómo se puede contribuir desde abajo, desde la sociedad, a fijar las prioridades políticas y a mover a la acción a los grupos parlamentarios y al Gobierno en pos, en este caso, de un objetivo, la transparencia, que, de suyo, tiende a provocar la cautela cuando no el vértigo en la mente de los legisladores y de los administradores, incluso de aquellos que están convencidos, en el plano teórico, de sus evidentes y contrastadas bondades. Otro aspecto positivo del proceso es que ha puesto a las claras algo que se ha evidenciado en el casi centenar de países que han aprobado ya sus respectivas leyes: que se trata de una iniciativa en torno a la cual podría obtenerse un alto grado de consenso político, mediático y social, pues, es, en cierto modo, previo a las diferentes ideologías, ya que entronca con el propio concepto de construcción y profundización de una democracia real.

\section{ANÁLISIS DEL PROYEGTO DE LEY: LUGES Y SOMBRAS. MATERIALES PARA UN DEBATE}

El Proyecto se divide en dos Títulos: Transparencia de la Actividad Pública y Buen Gobierno. El Gobierno ha decidido unir en un solo texto dos materias que, si bien pueden considerarse relacionadas, no suelen ser objeto de regulación unitaria en el Derecho comparado. Ha incluido también una disposición adicional dedicada a la revisión y simplificación normativa a la que están obligadas todas las Administraciones ${ }^{14}$. En estas páginas me dedicaré sólo a la transparencia y el acceso a la información ${ }^{15}$. La brevedad y finalidad de este escrito me impide, evidentemente, hacer un análisis detallado de la norma, de

\footnotetext{
13 Véase "Proposición de Ley relativa a la transparencia, acceso a la información pública y buen gobierno", presentada por el Grupo Parlamentario Popular en el Congreso, Boletín Oficial de las Cortes Generales. Congreso de los Diputados, de 15 de julio de 2011, núm. 326-1. Entre las diferencias con el posterior Proyecto que comentamos, las más llamativas son la ausencia de previsión de un órgano de control independiente y la limitación de las normas de buen gobierno a meros principios éticos, publicación de información sobre retribuciones y reglas sobre el tratamiento oficial de los miembros del Gobierno y altos cargos.

${ }^{14}$ Disposición adicional segunda.

${ }^{15}$ El Título dedicado al Buen Gobierno, que dejaré básicamente fuera de este estudio, establece, en síntesis, en relación a los miembros del Gobierno y altos cargos de todas las Administraciones y entidades de Derecho público o privado, principios éticos y de actuación (art. 23, con base en el Código de buen gobierno de 2005), e infracciones en materia de conflicto de intereses (art. 24), económico-presupuestaria (art. 25, ampliando las de la Ley General Presupuestaria y la Ley Orgánica de Estabilidad Presupuestaria y Sostenibilidad Financiera) y disciplinaria (art. 26, extendiendo a los sujetos mencionados las de la Ley
} 
tal modo que sólo apuntaré los elementos básicos de modo crítico, subrayando lo que a mi juicio son luces y sombras, como materiales para un debate ${ }^{16}$.

\section{1. Ámbito objetivo de aplicación. El entronque con la normativa sobre acceso a los archivos y sus aporías.}

Conforme establece la disposición adicional primera, se rige por la normativa sobre procedimiento administrativo el acceso por los interesados a los documentos que se integren en un procedimiento en curso.

del Estatuto Básico del Empleado Público) y contempla un listado de sanciones, que en el caso de las económico-presupuestarias y de las disciplinarias graves y muy graves pueden ser una o más de entre la declaración del incumplimiento y su publicación en el Boletín Oficial del Estado, la destitución en los cargos públicos que ocupen, la no percepción de pensión indemnizatoria o la inhabilitación durante un período de entre cinco o diez años. Si bien es cierto que la proposición de ley del PP de 28 de junio de 2011 ya incluía la vertiente llamada "Buen gobierno", el Anteproyecto lo desarrolla en mucha mayor extensión, profundidad y contundencia, dado que la versión anterior sólo incluía a los miembros del Gobierno y Altos Cargos de la AGE y se limitaba a referir los principios éticos y de actuación ya acogidos en el Código de Buen Gobierno y a prescribir la publicación electrónica nominativa de sus retribuciones y establecer como única denominación en el tratamiento oficial la de señor/señora. La dramática situación económica e institucional de nuestro país parece haber llevado al Gobierno, probablemente a iniciativa del Ministerio de Hacienda, a la convicción de la necesidad de un "golpe legislativo de autoridad". A mi juicio, se trata no obstante de una regulación que necesita ser repensada con sumo cuidado: el carácter genérico de los tipos infractores, en muchos casos además con incapacidad para discernir el responsable, su solapamiento con tipos penales, su contradicción con las previsiones constitucionales, estatutarias y orgánicas en la legislación sobre régimen electoral acerca de las causas y modos de cese en las funciones de los miembros de los Ejecutivos, la contundencia de las sanciones previstas y la posible reserva constitucional para su imposición por los tribunales. Mención aparte merece la atribución de la competencia para imponer estas las sanciones. En el primer Anteproyecto se preveía que en el caso de los miembros del Gobierno de la Nación y Secretarios de Estado la competencia para ordenar la incoación correspondía al Consejo de Ministros a propuesta del Ministro de Hacienda y Administraciones Públicas. En los demás supuestos, adviértase, cualquiera que fuera la Administración competente, al propio Ministro de Hacienda y Administraciones Públicas. En el segundo Anteproyecto y en el posterior Proyecto de Ley se precisa que si se trata de otras Administraciones, la competencia pertenece a dichos órganos del Estado sólo respecto de las infracciones en materia económico-presupuestaria, ya que en los demás casos corresponde la incoación, instrucción y resolución a los órganos que tengan atribuidas estas funciones en aplicación del régimen disciplinario propio de las Comunidades Autónomas o Entidades Locales en las que presten servicios los presuntos responsables (bien que hay que recordar que el régimen disciplinario en dicha normativa se refiere al aplicable a los empleados públicos, y no a las autoridades). Por lo demás, la Disposición final octava refiere como título competencial que ampara la ley los artículos $149.1 .1^{\mathrm{a}}, 149.1 .13^{\mathrm{a}}$ y $149.1 .18^{\mathrm{a}}$. Puede interpretarse que lo relativo a infracciones relacionadas con la gestión económico-financiera es lo que justifica la mención al artículo 149.1.13 a -bases y coordinación de la planificación general de la actividad económica- lo que supone, por lo demás, una interpretación de este título extraordinariamente incisiva.

${ }^{16}$ Un estudio prospectivo lo realicé en Transparencia y acceso a la información pública en España: análisis y propuestas legislativas, Fundación Alternativas, Madrid, 2011

Revista Andaluza de Administración Pública

ISSN: 0034-7639, núm. 84, Sevilla, septiembre-diciembre (2012), págs. 89-134 
Asimismo, se regulan por su normativa específica aquellas materias que tengan un régimen legal específico de acceso a la información ${ }^{17}$. En el caso del acceso a la información ambiental ${ }^{18}$, la reutilización de la información públi$\mathrm{ca}^{19}$ y el acceso a la información obrante en archivos que no sean de gestión u oficina (esto es, generales o centrales, intermedios e históricos).

Esta última previsión resulta a mi juicio sumamente desafortunada, por muchos motivos. En primer lugar, porque opera con unas categorías archivísticas que no necesariamente son comunes a todas las legislaciones autonómicas. En segundo lugar, en la medida en que va a hacer depender el derecho de los ciudadanos a conocer la información en poder de la Administración en cuanto a los sujetos obligados, a la publicidad activa y a las condiciones sustantivas y procedimentales de ejercicio del derechos de acceso de algo tan en buena medida discrecional como el tipo de archivo en el que conste cada tipo de información, lo que además, varía en las prácticas de cada Comunidad Autónoma e incluso de los diferentes Ministerios. Es más, algunas solicitudes se van a regir, en parte, por una normativa, y en parte por otra, en función de donde se halle cada parte de la información solicitada. Al respecto, en la regulación actualmente en vigor, hay que reseñar la absoluta deficiencia e incoherencia de la regulación legal "en paralelo" que llevan a cabo la Ley 30/1992, de 26 de noviembre, de Régimen Jurídico de las Administraciones Públicas y del Procedimiento Administrativo (LRJAP-PAC) y la Ley 16/1985, de 25 de junio, del Patrimonio Histórico Español (LPHE), y que ha dado origen a una extraordinaria confusión en una cuestión básica que debiera estar meridianamente clara en pro de la seguridad jurídica, cual es la de la normativa aplicable a las solicitudes de acceso a la información. Por una parte, el artículo 37 de la Ley 30/1992, de 26 de noviembre, de Régimen Jurídico de las Administraciones Públicas y del Procedimiento Administrativo Común regula con carácter básico el derecho "a acceder a los registros y a los documentos que, formando parte de un expediente, obren en los archivos administrativos [...] siempre que tales expedientes correspondan a procedimientos terminados en la fecha de la solicitud". Como puede verse, la ley no distingue en función de la antigüedad del documento o el tipo de archivo en que se encuentre, salvo, en su apartado 5.g) para excluir de su regulación "la consulta de fondos documentales existentes en los Archivos Históricos" y, es más, regula la modalidad de consulta directa de los expedientes "cuando los solicitantes sean investigadores que acrediten un

\footnotetext{
${ }^{17}$ Como es el caso, entre otros, del acceso de los concejales a la información municipal, regulado en los artículos 77 LRBRL y 14 del ROF.

${ }^{18}$ Ley 27/2006, de 28 de julio, de acceso a la información ambiental.

${ }^{19}$ Ley $37 / 2007$, de 16 de noviembre, de reutilización de la información del sector público.
} 
interés histórico, científico o cultural relevante". De todo ello parecería concluirse que esta Ley regula con carácter básico el acceso a cualquier documento administrativo, salvo los obrantes en archivos históricos (incluyendo, por tanto, los que se hallan en archivos de oficina o de gestión, generales o centrales e intermedios). Por otra parte, y en contraste, la Ley 16/1985, de 25 de junio, del Patrimonio Histórico Español (LPHE), pese a considerar que cualquier documento administrativo forma parte del mismo, cualquiera que sea su antigüedad y el tipo de archivo en el que obre ${ }^{20}$, regula en su artículo 57 el régimen sustantivo del acceso a los documentos administrativos estatales sólo una vez abandonan los archivos de oficina o de gestión y pasan a los centrales, y remite al desarrollo reglamentario las condiciones para la realización de las consultas y la obtención de reproducciones. Por tanto regula el acceso a los documentos obrantes en archivos generales o centrales, intermedios e históricos, en contradicción con el ámbito de aplicación del artículo 37 LRJAP-PAC. Tuvieron que pasar más de veinticinco años para que el Gobierno se decidiera a llevar a cabo el desarrollo reglamentario de la regulación legal de los archivos de titularidad estatal, por Real Decreto 1708/2011, de 18 de noviembre, por el que se establece el Sistema Español de Archivos y se regula el Sistema de Archivos de la Administración General del Estado y de sus Organismos Públicos y su régimen de acceso (RDA). Esta norma distingue entre archivos de oficina o de gestión, generales o centrales, intermedio e histórico (art. 8) y regula en su Capítulo IV el "procedimiento de acceso a documentos y archivos" (arts. 23 a 32), que se aplica a todos los archivos que no tengan la consideración de archivos de oficina o de gestión. Parece que hay aquí un intento de salvar la contradicción legal y de apostar por la lógica del artículo 57 LPHE. De este modo, el RD, con insuficiencia de rango legal -como era la previsión inicial- $\mathrm{y}$ proviniendo la iniciativa del Ministerio de Cultura, se alineó con la normativa "propia" de dicho Ministerio, la Ley de Patrimonio Histórico.

${ }^{20}$ S. FERNÁNDEZ RAMOS (véase, en especial, "Políticas y normativas archivísticas", Congreso Los archivos municipales en la España democrática, Zaragoza, octubre de 2005, gentilmente puesto a mi disposición por su autor) ha explicado claramente en diversos escritos las "razones" históricas de la peculiaridad española acogida en el artículo 49.2 LPHE, que considera integrantes del patrimonio documental todos los documentos administrativos ("Forman parte del patrimonio documental los documentos de cualquier época generados, conservados o reunidos en el ejercicio de su función por cualquier organismo o entidad de carácter público, por las personas jurídicas en cuyo capital participe mayoritariamente el Estado u otras Entidades públicas y por las personas privadas, físicas o jurídicas, gestoras de servicios públicos en lo relacionado con la gestión de dichos servicios.") y en consecuencia asocia los archivos - todos ellos, con independencia de la antigüedad de la documentación y de su valor histórico- al título competencial relativo al patrimonio cultural, y la enorme disfunción jurídica, organizativa y funcional que ello ha generado. 
Ahora bien, una vez emprendida la tarea legislativa de modificar el artículo 37 LRJAP-PAG y sustituirlo ya por una Ley de Transparencia y Acceso, lo más efectivo y acorde con el Derecho comparado sería, a nuestro juicio, por el contrario, establecer que esta nueva norma se aplica a cualquier tipo de información, excluida acaso la obrante en archivos históricos (que, en el caso de los estatales, sí podrían regirse por lo dispuesto en la Ley de Patrimonio Histórico y en el RDA, dado que en ellos sí el interés cultural es el prevalente, y no el de la transparencia de la gestión pública, lo que justifica que puedan y deban establecerse disposiciones específicas en cuanto a los límites o a los modos de acceso).

Sin embargo, el Proyecto se ha alineado con la lógica del RD de 2011, pocos meses anterior a la aprobación del Anteproyecto y al que mantiene en vigor, de modo que el régimen sustantivo y procedimental de acceso a los documentos que obran en archivos de oficina o gestión es el establecido en la Ley de Transparencia mientras que si se encuentran en archivos centrales, intermedios e históricos es el recogido en la normativa archivística. De mantenerse así, dará lugar a grandes disfuncionalidades e incoherencias.

Por lo demás, la regulación del Proyecto es, no obstante, supletoria en lo no regulado, lo que tiene una importancia decisiva, en especial, en materia de reclamaciones frente a decisiones sobre acceso, como veremos.

\section{La naturaleza del derecho, la base competencial y los sujetos obligados.}

En España, el artículo 105.b) de la Constitución llama a la ley a regular el acceso de los ciudadanos a los archivos y registros administrativos, salvo en lo que afecte a la seguridad y defensa del Estado, la averiguación de los delitos y la intimidad de las personas. No se inserta en el Título I "De los derechos y deberes fundamentales"), sino en el IV ("Del Gobierno y de la Administración"). En su momento fue una decisión pionera la de elevar el derecho a rango constitucional pero actualmente condiciona la aproximación jurídica. Por la peculiar distinción entre categorías de derechos, peculiar de nuestra Constitución, y por la ubicación del artículo 105, el tratamiento hasta el momento en nuestro Derecho ha sido el de un derecho autónomo respecto del derecho fundamental a la libertad de información, un "derecho de configuración legal", desarrollado por leyes ordinarias (Ley de procedimiento administrativo, Ley de reutilización de la información pública) y aplicable sólo al poder ejecutivo. Han sido aprobadas con apoyo en el título competencial del art. 149.1.18 (bases del régimen jurídico de las Adminis- 
traciones Públicas). No se aplican, por ello mismo, a los demás poderes y órganos constitucionales (algunos de los cuales tienen sus propias regulaciones en materia de publicidad). No se han presentado, pues, como desarrollo del art. 20.1.d) CE (y por ello, no son leyes orgánicas ni están protegidas por el recurso de amparo). En la línea de la no consideración del derecho de acceso como integrante de la libertad de información se mueve también una jurisprudencia muy escasa y que no aborda frontalmente la cuestión general de las relaciones entre ambos derechos $^{21}$, si bien en la más reciente se prefiere mantener la cuestión imprejuz$\operatorname{gada}^{22}$. Y, en esta misma, línea, el Proyecto lo es también de ley ordinaria y enlaza expresamente en su artículo 8 con el artículo 105.b) de la Constitución y no con la libertad de información, y éste ha sido probablemente su aspecto más polémico y criticado.

La doctrina ha discutido tradicionalmente sobre si el derecho de acceso es un derecho autónomo (y por ende no fundamental en nuestro esquema constitucional $)^{23}$ o, por el contrario, de una manifestación de la libertad de información con relación directa con el principio de democracia ${ }^{24}$. Esta es la posición de la doctrina más actualizada.

En el Derecho europeo y comparado, el derecho de acceso a la información

${ }^{21}$ Véase al respecto STC 161/1988, de 20 de septiembre, que inadmite parcialmente un recurso de amparo en el que se invoca el artículo 105.b), si bien ha de tenerse en cuenta que en este caso no se alegaba la conexión de este precepto con el artículo 20.1.d). En la jurisprudencia del Tribunal Supremo es reiterada esta aproximación: "El artículo 105 b) de la Constitución dispone que la ley regulará, entre otras materias, 'El acceso de los ciudadanos a los archivos y registros administrativos, salvo en lo que afecte a la seguridad y defensa del Estado, la averiguación de los delitos y la intimidad de las personas'. Este precepto constitucional remite expresamente a la configuración legal el ejercicio del derecho de acceso a los archivos y registros administrativos, como derecho no fundamental, aunque relacionado con el derecho de participación política, con el de libertad de información y con el de tutela judicial efectiva. Refleja una concepción de la información que obra en manos del poder público acorde con los principios inherentes al Estado democrático (en cuanto el acceso a los archivos y registros públicos implica una potestad de participación del ciudadano y facilita el ejercicio de la crítica del poder) y al Estado de derecho (en cuanto dicho acceso constituye un procedimiento indirecto de fiscalizar la sumisión de la Administración a la ley y de permitir con más eficacia el control de su actuación por la jurisdicción contencioso-administrativa)".

${ }^{22}$ La recentísima STS de 29 de mayo de 2012 dice "aun admitiendo a efectos puramente argumentativos que los arts. 20.1.d) y 23.1 CE engloban el derecho a obtener información de los poderes públicos - algo que dista de ser evidente-..."

23 ÁLVAREZ RICO, M. (1979), "El derecho de acceso a los documentos administrativos", Documentación Administrativa, núm. 183, pp. 103-133; Pomed Sánchez, L. A. (1989), El acceso de los ciudadanos a los archivos y registros administrativos, INAP. Madrid.

${ }^{24}$ FERNÁNDEZ RAMOS, S. (1997), El derecho de acceso a los documentos administrativos, Marcial Pons, Madrid; VILLAVERDE MENÉNDEZ, I. (1995), Los derechos del público, Tecnos, Madrid. 
ha ido adquiriendo rango de derecho fundamental, bien como derecho autónomo (en las declaraciones de derechos fundamentales más jóvenes, como la Carta de los Derechos Fundamentales de la Unión Europea, proclamada el 7 de diciembre de 2000, en su artículo 42), bien como parte del contenido de la libertad de información-expresión (en los sistemas iusfundamentales menos recientes, como ha ocurrido en el sistema del Convenio Europeo de Derechos Humanos, a partir de una reinterpretación del contenido de su artículo $10^{25}$ ).

A mi juicio, una interpretación evolutiva del derecho fundamental a la libertad de información a la luz del Convenio Europeo de Derecho Humanos, a la que remite de forma expresa el artículo 10.2 de la Constitución, permitiría abordar una nueva perspectiva, la de considerar el derecho de acceso como integrante de la libertad de información, que sería en todo caso la pertinente si se pretendiera extender su ámbito subjetivo a todos los poderes públicos de cualquier ámbito territorial, y dotarlo de la mayor garantía que supone la reserva de ley orgánica y el recurso de amparo constitucional. Una interpretación conforme a los instrumentos internacionales de derechos fundamentales suscritos por España, en particular a la luz del Convenio Europeo de Derechos Humanos, siendo así que me parece incuestionable que poca información hay más relevante para la creación de una opinión pública informada, a cuyo servicio está la libertad de información, que, precisamente, la que obra en manos de los poderes públicos. Si en la jurisprudencia constitucional este derecho conecta directamente con el propio principio de Estado democrático, que precisa de una opinión pública informada, y esta afirmación se hace incluso respecto a información sobre personajes famosos, con cuánta mayor razón puede predicarse esto mismo de información que detenta la propia Administración relacionada con la gestión de los asuntos públicos. Desde el punto de vista sociológico en un momento en que existe un clamor a favor de la transparencia y el acceso a la información, el tratamiento de este derecho como un derecho "de segundo rango" parece situarse fuera de esta concepción social y ha sido, como decimos, el punto más controvertido del Proyecto ${ }^{26}$. Se aduce que se trataría de un derecho más desprotegido, al tener una consideración inferior a

${ }^{25}$ Dos asuntos han tenido como protagonista a uno de los países con la legislación más favorable a la publicidad, Hungría. En ambos, el Gobierno húngaro partía de que, en efecto, una denegación de información constituye una injerencia en la libertad de expresión del artículo $10 \mathrm{CEDH}$, enfoque que ha sido acogido por el TEDH. Se trata de los asuntos Társaság a Szabadságjogokért, sentencia de 14 de abril de 2009, y Kennedy, sentencia de 16 de agosto de 2009. Es también la solución a la que se ha llegado en la jurisprudencia de la Corte Iberoamericana de Derechos Humanos de 19 de septiembre de 2006, en el caso Claude Reyes y otros contra Chile, interpretando el artículo 13 de la Convención).

${ }^{26}$ La reivindicación de la consideración del derecho de acceso como derecho fundamental ha sido, probablemente, la más reiterada entre los grupos pro acceso, la prensa y en la consulta pública (como se 
otros derechos enfrentados, que sí se han reconocido como fundamentales y tender a ser postergado frente a éstos, en particular, frente al derecho a la intimidad y a la protección de datos ${ }^{27}$, y al no estar protegido por el recurso de amparo.

Se trataría, pues, de una reinterpretación de la libertad de información del art. 20.1.d), en línea con el Derecho europeo y comparado y con la doctrina sobre la materia. No parece lo más probable, aunque no es descartable, que, fundado en la evolución del Derecho internacional y europeo el Tribunal Constitucional fuera a pronunciarse en contra de esta opción (máxime cuando ha desplegado una jurisprudencia realmente "creativa" en relación con el derecho a la protección de datos). Ello es compatible con dotar del rango de orgánicas a las disposiciones sobre el ámbito, el contenido del derecho y sus límites, y establecer un régimen diferenciado en función del sujeto obligado, por leyes ordinarias, para los mecanismos de publicidad activa, el procedimiento de ejercicio del derecho y las reclamaciones contra las inadmisiones o las denegaciones totales o parciales para los sujetos actualmente contemplados en el Proyecto, pudiendo mantenerse para la información relacionada con el ejercicio de actividades administrativas (en el sentido amplio del Proyecto) la regulación en él contemplada. Si, por el contrario, se prefiere optar por una opción jurídicamente más conservadora, considerando el derecho de acceso un derecho autónomo respecto a la libertad de información, contenido en el artículo 105 de la Constitución y aplicable sólo a las funciones administrativas, se podría tal vez optar por un término medio, y prever que su protección judicial en los tribunales contencioso-administrativos se lleve a cabo a través del procedimiento

reconoce en el "Informe sobre la consulta pública electrónica del Anteproyecto" elaborado por el propio Ministerio de la Presidencia), así como de expertos como el informe de la Oficina del Representante para la Libertad de los Medios de Comunicación de la Organización para la Seguridad y la Cooperación en Europa (OSCE). Además, otra de las críticas más generalizadas es que no alcanza a todos los poderes y órganos constitucionales (entre ellos, la Casa Real), lo que deriva precisamente de su consideración como un derecho "administrativo".

${ }^{27}$ En cuando a lo primero, la tramitación del anteproyecto parece darles la razón, pues en el propio Informe de la Agencia Española de Protección de Datos se lee: "No debe olvidarse en este punto que el derecho fundamental a la protección de datos aparece reconocido expresamente por la Sección segunda del Capítulo I del Título I de la Constitución, mientras que el derecho de acceso a la información pública, aun siendo una garantía esencial de funcionamiento del Estado democrático, no aparece incluido en el catálogo de derechos fundamentales y libertades públicas recogido en la Constitución”. El propio Informe trasluce una concepción restrictiva y en ocasiones errónea de la transparencia por relación a la protección de datos. La afirmación es paradójica por cuando el derecho a la protección de datos no aparece en el catálogo de derechos fundamentales y ha sido extraída por el Tribunal constitucional de la mera referencia del art. 18.4 CE a la limitación de la informática (siendo así, además, que también se aplica a los tratamientos no informatizados...). 
previsto en los artículos 114 a 122 de la Ley de dicha jurisdicción, que si bien se prevé para el procedimiento de amparo judicial de las libertades y derechos previsto en el art. 53.2 CE (de hecho ese mismo artículo competencial lo extiende a la objeción de conciencia del art. $30 \mathrm{CE}$, que no es un derecho fundamental). Sería una extensión legal de un procedimiento judicial preferente sin otorgarle naturaleza de derecho fundamental ni abrir la vía de amparo constitucional y para la que bastaría ley ordinaria dado que ese es el rango de la propia Ley de la jurisdicción contencioso-administrativa.

El Proyecto, al considerarse desarrollo del artículo 105.b) se apoya en dos títulos competenciales en lo que se refiere a transparencia y acceso a la información ${ }^{28}$. Aunque el legislador no lo precisa, parece haber interpretado que el artículo 149.1.18 es la base competencial principal, y que el artículo 149.1.1 ${ }^{\mathrm{a}}$ actúa como complemento para el diseño de la necesaria existencia de un órgano independiente de resolución de reclamaciones (a semejanza de lo que hiciera la Ley orgánica 15/1999, de 13 de diciembre, de protección de datos personales, con refrendo por la STC 290/2000), y regula, de este modo, la transparencia y el acceso a la información administrativa, y no la legislativa o judicial, lo que ha recibido críticas por parte de diversas instituciones y organizaciones no gubernamentales. No obstante, hay que reconocer que se encuentra en esto la línea más general del Derecho comparado y es en todo caso lo único coherente con la base competencial utilizada, de modo que la publicidad de las actuaciones de otros poderes del Estado distintos al Ejecutivo por su actividad característica, no administrativa, queda fuera del Proyecto ${ }^{29}$. Se acoge, pues, una noción funcional de Administración, que incluye a todas las Administraciones y sus entidades instrumentales, también las Entidades gestoras y los Servicios comunes de la Seguridad Social ${ }^{30}$, a las Corporaciones de Derecho Público y a los órganos constitucionales (entre los que se incluye al CGPJ pero no a las actividades administrativas de las salas de gobierno de juzgados y tribunales) y las instituciones autonómicas análogas "en relación con sus actividades sujetas a Derecho administrativo". Probablemente sería conveniente sustituir esta expresión por una referencia a sus actividades en materia de "personal, bienes o contratación", pues de lo contrario quedarán fuera del conoci-

\footnotetext{
${ }^{28}$ Pues también apela, como dijimos, al artículo 149.1.13 ${ }^{\mathrm{a}}$-bases y coordinación de la planificación general de la actividad económica- probablemente como amparo de las disposiciones de buen gobierno en materia de sanciones por incumplimiento de normas económico-financieras.

${ }^{29}$ En España, en todo caso, la Constitución prevé la publicidad de las actuaciones de los diferentes poderes públicos, que están desarrolladas en el Reglamento del Congreso de los Diputados y del Senado, para el Poder Legislativo, y en la LOPJ, para el Judicial.

30 Novedad del Proyecto respecto del Anteproyecto.
} 
miento público la información sobre estas materias cuando se encuentren bajo un régimen de Derecho civil, mercantil o laboral.

Además, se va más allá, ampliando el radio de aplicación a las sociedades mercantiles en cuyo capital social la participación, directa o indirecta, pública sea mayoritaria (se ha apuntado, entre otros, por el Observatorio de la Contratación Pública, que debería acudirse más bien al concepto de poder adjudicador del artículo 3.1.h) de la Ley de contratos) ${ }^{31}$, a las fundaciones del sector público (se utiliza aquí una terminología un tanto restrictiva por "estatalista") y a las asociaciones constituidas por las Administraciones, organismos y entidades antes mencionadas, así como, siguiendo una sugerencia del Consejo de Estado, a los órganos de cooperación interadministrativa (en cuyo caso será la Administración que ostente la secretaría la que deba cumplir con las obligaciones).

Obsérvese que el Proyecto no incluye al Gobierno de la Nación, tal vez por entender que, por una parte, se trata de un órgano "mixto" político-administrativo y, por otra, la información que maneja es aportada o custodiada por órganos integrados en la AGE, pero lo cierto es que el Convenio 205, que, como decimos, España pretende ratificar, sí obliga expresamente a su inclusión.

En el caso de las personas físicas y jurídicas que presten servicios públicos o ejerzan potestades administrativas, están obligadas a suministrar, previo requerimiento, a la Administración, organismo o entidad de los anteriormente descritos al que se encuentren vinculadas toda la información necesaria para el cumplimiento por aquélla de las obligaciones previstas en esta Ley. Esta obligación se extiende (es una novedad de la segunda redacción del Anteproyecto que se ha mantenido en el Proyecto) a los adjudicatarios de contratos del sector público en los términos previstos en el respectivo contrato. Esta última previsión me parece, en línea con la observación del Consejo de Estado, criticable por ambigua y por poder llevar a efectos contrarios a la transparencia pretendida ${ }^{32}$.

31 " Cualesquiera entes, organismos o entidades con personalidad jurídica propia, que hayan sido creados específicamente para satisfacer necesidades de interés general que no tengan carácter industrial o mercantil, siempre que uno o varios sujetos pertenecientes al sector público financien mayoritariamente su actividad, controlen su gestión, o nombren a más de la mitad de los miembros de su órgano de administración, dirección o vigilancia."

${ }^{32}$ En palabras del Consejo de Estado: "debería valorarse la conveniencia de modificar el inciso final de este apartado, que, en el caso concreto de los adjudicatarios de contratos del sector público, remite la determinación del contenido y la extensión de esta obligación a lo que disponga el respectivo contrato. 
No se han incluido tampoco a los partidos políticos y sus fundaciones y asociaciones, al no ser sujetos públicos ni entrar, en el concepto, por amplio que se quiera, de Administración o de ejercicio de funciones administrativas ${ }^{33}$. Esta exclusión ha generado críticas en diversos medios (doctrinales, periodísticos, ONGs de transparencia) ${ }^{34}$, máxime en un contexto de escándalos de financiación ilegales que han asolado este país y llevado la credibilidad de los políticos en la percepción de los ciudadanos a su mínimo histórico desde que hay registros del Centro de Investigaciones Sociológicas ${ }^{35}$. La financiación está regulada en la Ley Orgánica 8/2007, de 4 de julio, de Financiación de Partidos Políticos, recientemente reformada por la Ley Orgánica 5/2012, de 22 de octubre. Ciertamente, dicha Ley establece la obligación de presentar las cuentas anuales, que deben ser fiscalizadas por el Tribunal de Cuentas, y tras la reforma, obliga a los partidos políticos, una vez por el Tribunal de Cuentas el informe de fiscalización correspondiente a un determinado ejercicio, a hacer

Una previsión de estas características permitiría dejar a la voluntad de las partes la regulación concreta de esta obligación, pudiendo llegar a quedar desplazadas las entidades, organismos y órganos que, a los efectos del anteproyecto, tienen las consideración de Administraciones Públicas."

${ }^{33}$ En palabras del Consejo de Estado: "Junto a las observaciones anteriores, ha de realizarse una última reflexión en relación con el ámbito subjetivo de aplicación del título I del anteproyecto. No se ha incluido en él ni a los partidos políticos ni a los sindicatos, opción ésta que, desde el punto de vista de la técnica, el Consejo de Estado no considera objetable, habida cuenta de que estas entidades no participan de la misma naturaleza que el resto de los sujetos mencionados en el artículo 2. Ello no obstante, sí se considera oportuno incluir en el anteproyecto alguna referencia expresa a ellos y a la necesidad de hacer extensivo a su ámbito de actuación el principio de transparencia, especialmente en lo relativo a los fondos públicos que perciben y al uso que de tales fondos realizan, debiendo articular adecuadamente la previsión que a este respecto se introduzca en el anteproyecto con las contenidas en la regulación aplicable a la financiación de partidos políticos y sindicatos".

${ }^{34}$ Por todos, véase la intervención de Jesús Lizcano, Presidente de Transparencia Internacional España, en la primera sesión de las comparecencias de expertos ante la Comisión Constitucional del Congreso de los Diputados sobre el Proyecto de Ley: http://www.elmundo.es/elmundo/2013/01/27/espana/1359278596.html; y $\quad$ http://politica.elpais.com/politica/2013/01/23/actualidad/1358971062_797581.html. Puede acceder al video de dichas comparecencias en la página www.congreso.es y en el Diario de sesiones.

${ }^{35}$ La insatisfacción va en aumento. En el barómetro del Centro de Investigaciones Sociológicas de diciembre de 2012 el porcentaje de españoles que ven a los políticos y la case política como uno de los principales problemas del país es del 29,8\% (seguido por un 17,1\% de "la corrupción y el fraude"), sólo por detrás del paro y de la situación económica. Para el 11,2\% de los ciudadanos, era el principal problema, incluso por encima de los dos anteriores (y "la corrupción y el fraude" para el 6,2\%). Como principal objetivo de España para los cinco próximos años, los ciudadanos citan la lucha contra la corrupción política en un primer lugar en un 16,5\% (sólo por detrás de la lucha contra el paro) y en el segundo lugar en un destacado primer puesto con el 30,2\%. Sin embargo prevén mayoritariamente que al cabo de esos cinco años, la corrupción política habrá aumentado (en un 49,6\% que supera incluso la suma de los que creen que se habrá mantenido o que habrá disminuido). Puede consultarse en: http://www.cis.es/cis/export/sites/default/-Archivos/Marginales/2960_2979/2972/e297200.html. 
públicas, preferentemente a través de su página web, el balance y la cuenta de resultados y, en particular, la cuantía de los créditos que les han sido concedidos, el tipo de entidad concedente y las condonaciones de deuda correspondientes a tal ejercicio, de forma que esta información sea de gratuito y fácil acceso para los ciudadanos, lo que supone un avance. No obstante, como puede verse, no es una obligación de publicitar todo el estado de ingresos y gastos y opera de forma tardía en el tiempo (habida cuenta de la politización y los injustificables retrasos del Tribunal de Cuentas). Además, la Ley dispone que el importe global de las subvenciones públicas ha de consignarse en la Ley de Presupuestos Generales de cada ejercicio, y es por tanto público, así como lo son los criterios de reparto. No obstante, también ha procedido a la relajación de los límites en cuanto a la financiación de las fundaciones de los partidos políticos, que, a diferencia de éstos, pueden recibirlas de empresas que contratan con Administraciones Públicas y no están sometidas al límite anual de los 100.000 euros por donante, y no tienen consideración de donaciones las cantidades o bienes entregados para financiar una actividad o proyecto concreto, cuando se realice como consecuencia de un interés común derivado de las actividades propias del objeto societario o estatutario de ambas entidades. Ciertamente, estas fundaciones y asociaciones están obligadas a informar anualmente al Ministerio de Hacienda y Administraciones Públicas de todas las donaciones y aportaciones, y a notificar al Tribunal de Cuentas las recibidas de personas jurídicas, pero eso no implica el conocimiento ni el control ciudadanos, salvo acaso por vía indirecta, precisamente ejerciendo ante éstos el derecho de acceso.

Por lo demás, otras entidades que tienen un reconocimiento constitucional y se financian fundamentalmente con fondos públicos son los sindicatos y las organizaciones empresariales, y su exclusión ha sido también objeto de crítica $^{36}$.

En todo caso, debe matizarse que, como veremos a continuación, el Proyecto prevé la publicidad de toda subvención otorgada por una entidad pública sometida a su ámbito de aplicación. La posible ampliación a todos los sujetos que reciben fondos públicos (como permite, que no impone, el Convenio 205) creo que hubiera complicado en exceso el sistema, en su generalidad (hasta un alumno de secundaria con beca o un joven trabajador autónomo con

\footnotetext{
${ }^{36}$ En el "Informe sobre la consulta pública electrónica del Anteproyecto" del Ministerio de la Presidencia se apunta que las observaciones formuladas pretendían principalmente la inclusión de todos los receptores de fondos públicos, incluidos sindicatos, patronal y ONGs.
} 
subvención lo hacen), cuando, como veremos, el Proyecto ya obliga a hacer públicas todas las subvenciones y ayudas.

\section{La publicidad activa.}

Las leyes de transparencia y acceso a la información existentes en otros países se han ido adaptando a la sociedad digital de la información del nuevo milenio, dando el salto cualitativo de la publicidad pasiva a la publicidad activa, y estableciendo disposiciones todo lo precisas posible que obliguen a poner a disposición de todos los ciudadanos en Internet la principal información que les permita participar, controlar y con ello contribuir a una gestión pública más eficaz y transparente. Buena parte de esta información ya es objeto de publicidad oficial (como ocurre, en nuestro Derecho, con determinados actos en materia de empleo público, contratos, subvenciones, etc.); se trata, sobre todo, de centralizarla y ponerla en formatos que permitan su fácil localización y, en su caso, su posterior tratamiento y reutilización.

En este punto, el Proyecto es ambicioso. Prevé la publicidad activa por parte de los obligados (excluyendo a los sujetos privados antes apuntados) de la información cuyo conocimiento sea relevante para garantizar la transparencia de la actividad que esté relacionada con el funcionamiento y control de la actuación pública. La segunda redacción del Anteproyecto añadió que la publicación debe hacerse en las correspondientes sedes electrónicas y páginas web (no todos los obligados tienen sede electrónica ni son Administraciones Públicas) de manera clara, estructurada y entendible para los interesados, para lo que deben establecerse mecanismos adecuados para facilitar la accesibilidad, la interoperabilidad, la calidad y la reutilización de la información publicada así como su identificación y localización. Este añadido, que había sido objeto de diversas sugerencias, conecta además con las iniciativas de open data en que España se ha comprometido. Además, se introdujo en el Proyecto que toda la información estará a disposición de las personas con discapacidad en una modalidad accesible. Sin embargo, no se ha hecho mención del plazo de publicación y el tiempo en que la información ha de estar disponible, como se había sugerido en la consulta pública y constata el Informe del Ministerio de la Presidencia.

Aclara también que juegan en estos casos los mismos límites generales al derecho de acceso que estudiaremos más adelante, y, en particular, el derivado de la protección de datos de carácter personal (habiéndose incluido en el Proyecto, a sugerencia de la AEPD, que cuando la información contuviera datos es- 
pecialmente protegidos la publicidad sólo se llevará a cabo previa disociación de los mismos).

El Proyecto no se limita a establecer este principio general, sino establece obligaciones concretas de publicidad activa, de forma notablemente detallada, lo que me merece un juicio muy positivo.

a) Entre la información institucional, organizativa y de planificación se encuentra la relativa a funciones, normativa aplicable y estructura organizativa; planes y programas anuales y plurianuales, incluyendo objetivos, actividades, medios y tiempo previsto para su ejecución, con evaluación y publicación periódica de su grado de cumplimiento y resultados (estos últimos, a sugerencia del Consejo de Estado, y como ya había sido demandado en la consulta pública) y de los indicadores de medida y valoración.

En la consulta pública se sugirió, además, la publicación de la identificación de los responsables de todas las unidades que forman parte del organigrama de los sujetos obligados y los curricula vitae de los altos cargos y la publicación de sus agendas de reuniones y actividades. Asimismo, la coalición pro acceso ha sugerido la publicación del patrimonio de cada organismo público (que por lo demás debe constar el inventario de bienes y derechos). Todas estas propuestas, incluida la publicidad de las agendas ${ }^{37}$ me parecen razonables.

b) Entre la información de relevancia jurídica, junto con las directrices, instrucciones, circulares o respuestas a consultas planteadas por los particulares $\mathrm{u}$ otros órganos en la medida en que supongan una interpretación del Derecho -en línea con lo ya dispuesto en el 37.10 LRJAP-PAC- y además, y esto es nuevo, los anteproyectos de ley y los proyectos de reales decretos legislativos (introducido estos por sugerencia del Consejo de Estado pero con una defectuosa redacción, puesto que los decretos legislativos previstos en algunos Estatutos de Autonomía no tienen, obviamente, la calificación de "real", aspecto éste que pasó inadvertido al propio Consejo de Estado) y de reglamentos, así como las memorias u otros documentos, incluidos los informes, que integren los expedientes de elaboración de los textos normativos y los documentos que, conforme a la legislación sectorial vigente deban ser someti-

\footnotetext{
${ }^{37}$ En lo que están de acuerdo incluso la propia Asociación de Profesionales de las Relaciones Institucionales (APRI) (véase el artículo "Los profesionales de las Relaciones Institucionales piden que la Ley de Transparencia regule la actividad de los lobbys" (http://www.europapress.es/nacional/noticia-profesionales-relaciones-institucionales-piden-ley-transparencia-regule-actividad-lobbys-20120424170542.html)
} 
dos a un período de información pública durante su tramitación. La previsión es muy positiva, y la redacción es fruto de un cambio respecto a la primera redacción del Anteproyecto, en la medida en que ahora se incluyen los informes y los documentos sometidos a información pública. Más cuestionable es el momento en que han de someterse a publicidad estos textos, que está en función de que estén sometidos o no a dictamen preceptivo previo. De ser así, la publicación se prevé "cuando se soliciten los dictámenes" (en el caso de los anteproyectos de ley y de decretos legislativos) o "una vez que estos hayan sido solicitados" "sin que ello suponga necesariamente la apertura de un trámite de audiencia pública", en el caso de los reglamentos, disparidad ésta de redacción que parece injustificada y que en el segundo caso parece no establecer una necesaria simultaneidad. De no estar sujetos a dictamen preceptivo, la publicidad de los proyectos de ley y de decreto legislativo se realizará "en el momento de su aprobación" y queda sin determinar para los proyectos de reglamentos. Esta distinción era obviada en el Primer Anteproyecto y fue incorporada por sugerencias de los expertos. Como puede notarse, el momento (tardío) elegido desconecta la publicidad del servicio a un aumento de las posibilidades de participación ciudadana en el procedimiento normativo. Algo que por lo demás fue puesto de manifiesto en la consulta pública y en las reuniones de expertos. La reduce, en su caso, a la posibilidad de confrontar, en el caso de las normas sometidas a dictamen preceptivo, los textos enviados a dictamen y los aprobados como consecuencia de los cambios propuestos en los correspondientes dictámenes, lo cual al menos permite calibrar el grado de influencia de los órganos consultados sobre los órganos competentes para su aprobación. En el caso de las Memorias e informes y de los documentos sometidos a información pública, no se prevé el momento de publicación.

c) Finalmente, es muy destacable que se ha previsto la publicidad en materia económico-presupuestaria. Incluye:

- Todos (y no sólo los sometidos a publicidad oficial) los $\operatorname{contratos}^{38}$, con indicación del objeto, importe de licitación y de adjudicación, el procedimiento utilizado para su celebración, los instrumentos a través de los que, en su caso, se ha publicitado, el número de licitadores participantes en el procedimiento (acogiendo una propuesta del Observatorio de la Contratación Pú-

38 El Proyecto habla de "formalizados" pero, en la medida en que pudiera interpretarse como excluyendo de los contratos en que no hay una formalización procedimentalizada, creo que convendría eliminar esta referencia. 
blica en la consulta) y la identidad del adjudicatario, así como las modificaciones del contrato (se ha suprimido respecto del segundo Anteproyecto las prórrogas y las variaciones de plazo y precio, tal vez por entenderlas comprendidas, pero no siempre en las modificaciones, pero no siempre presuponen una modificación del contrato), las decisiones de desistimiento y renuncia (acogiendo una propuesta del Observatorio de la Contratación Pública en la consulta) y los datos estadísticos sobre el porcentaje en volumen presupuestario de contratos adjudicados a través de cada uno de los procedimientos previstos en la legislación de contratos del sector público. Acogiendo una propuesta del Observatorio de la Contratación Pública en la consulta, en el segundo Anteproyecto se ha añadido que la publicación de la información relativa a los contratos menores podrá realizarse trimestralmente y de forma agregada, expresión ésta que tiene cierta ambigüedad, siendo así que el Observatorio hablaba de "agrupada". Como es sabido, los contratos menores son objeto de adjudicación directa y precisamente por ello, son los que han generado una mayor opacidad, fraude y corrupción, con prácticas por todos conocidas de troceamiento artificial del objeto de los contratos para eludir la publicidad y concurrencia. Parece que debiera interpretarse que la agregación consiste en acumular los contratos suscritos por adjudicatario y por objeto, precisamente para prevenir este tipo de fraude. Por lo demás, se ha sugerido que podrían añadirse las actas de las comisiones de contratación ${ }^{39}$, lo que parece que puede compartirse.

- Todos los convenios suscritos (no sólo los interadministrativos), con mención de las partes, su objeto y, en su caso, las obligaciones económicas convenidas, a lo que a sugerencia de la Comisión Nacional de la Competencia y del Consejo de Estado, el Proyecto ha añadido el plazo de duración, modificaciones realizadas, obligados a la realización de las prestaciones. Además, a sugerencia del segundo se ha añadido la publicación de las encomiendas de gestión que se firmen, con indicación de su objeto, presupuesto, obligaciones económicas y las subcontrataciones que se realicen con mención de los adjudicatarios, procedimiento seguido para la adjudicación e importe de la misma.

- Todas las subvenciones y ayudas públicas concedidas con indicación de su importe, objetivo o finalidad y beneficiarios (y, nótese, no sólo las que dicha Ley obliga a publicar), si bien se considera como incluidas las reguladas en la Ley

39 Propuesto por los integrantes del Comité de Dirección de Transparencia Internacional España A. GARRIGUES WALKER, J. LIZCANO ÁLVAREZ, M. VILLORIA MENDIETA, J. SÁNCHEZ LAMBÁS, en "La Ley de Transparencia, sólo el primer paso", en el Diario El País, http://elpais.com/elpais/2012/03/29/opinion/1333034562_798871.html. 
38/2003, de 17 de noviembre, General de Subvenciones, lo que parece dejar fuera, pues, la excluidas del ámbito de aplicación de dicha ley, contempladas en su artículo 4, fundamental y significativamente, las subvenciones a grupos parlamentarios, partidos políticos y sus fundaciones ${ }^{40}$.

- Los presupuestos, con descripción de las principales partidas presupuestarias e información actualizada sobre su estado de ejecución.

- Las cuentas anuales que deban rendirse y los informes de auditoría de cuentas y los de fiscalización por parte de los órganos de control externo que sobre ellos se emitan. Se trata de un supuesto nuevo en el segundo Anteproyecto que se había propuesto en la Comisión de Expertos, que no obstante también habíamos hecho extensiva la obligación a los informes de los órganos de control interno.

- Las retribuciones percibidas por los altos cargos y máximos responsables de las entidades incluidas en el ámbito de la aplicación del Proyecto y, en el caso de la AGE, las resoluciones dictadas por la Oficina de Buen Gobierno y Conflictos de Intereses sobre la compatibilidad de las actividades privadas, que se suma a la publicación oficial de las declaraciones de actividades y de bienes y derechos, tanto de todo alto cargo estatal (no sólo, como hasta ahora, de Ministros y Secretarios de Estado) como de los representantes locales y los miembros no electos de la Junta de Gobierno local ${ }^{41}$. La redacción plantea el problema de que muchas de las entidades sujetas a la norma no acogen el concepto de "alto cargos" (entre otras muchas, las Universidades Públicas), lo que precisará de una tarea de interpretación. En la consulta pública se sugirió la publicación, también, de todas las retribuciones de funcionarios públicos.

- La publicación de la información estadística necesaria para valorar el gra-

\footnotetext{
40 “Quedan excluidos del ámbito de aplicación de esta Ley: a. Los premios que se otorguen sin la previa solicitud del beneficiario. b. Las subvenciones previstas en la Ley Orgánica 5/1985, de 19 de junio, del Régimen Electoral General c. Las subvenciones reguladas en la Ley Orgánica 3/1987, de 2 de julio, de Financiación de los Partidos Políticos. d. Las subvenciones a los grupos parlamentarios de las Cámaras de las Cortes Generales, en los términos previstos en los Reglamentos del Congreso de los Diputados y del Senado, así como las subvenciones a los grupos parlamentarios de las Asambleas autonómicas y a los grupos políticos de las corporaciones locales, según establezca su propia normativa.

${ }^{41}$ En los términos previstos en el artículo 14.4 de la Ley 5/2006, de 10 de abril, de Regulación de los Conflictos de Intereses de los Miembros del Gobierno y de los Altos Cargos de la Administración General del Estado, esto es, en BOE (en el caso de los Ayuntamientos, sólo si su Estatuto no ha dispuesto otra forma de publicación; en todo caso, parece que debiera haberse previsto en ese caso la publicación en el Boletín Oficial de la Provincia correspondiente).
} 
do de cumplimiento y calidad de los servicios públicos que sean de su competencia.

Sería conveniente, además, estimo, establecer de forma expresa la responsabilidad disciplinaria de los responsables de los incumplimientos o, cuando menos, la competencia de los órganos independientes de control en esta materia para declarar y hacer públicos estos incumplimientos.

Ha de advertirse, en todo caso, que el propio Proyecto prevé que estas obligaciones de transparencia "se entienden sin perjuicio de la aplicación de otras disposiciones específicas que prevean un régimen más amplio en materia de publicidad" (por ejemplo, en materia medioambiental o cualquiera otra disposición que establezca la publicidad de determinadas actuaciones).

En el ámbito de la AGE se crea un Portal de la Transparencia, dependiente del Ministerio de la Presidencia (extremo éste que aclara la segunda redacción), que facilite el acceso de los ciudadanos a la información antes reseñada, así como otra información cuyo acceso se solicite con mayor frecuencia, en los términos que se establezcan reglamentariamente. Todas las Administraciones pueden adoptar además medidas complementarias y de colaboración (añadido éste último de la segunda redacción) para el cumplimiento de estas obligaciones. En este sentido, puede bien pensarse en la prestación de soporte por las Comunidades Autónomas o las Diputaciones a los Municipios, o en una red de enlaces que faciliten al ciudadano localizar la información.

\section{El objeto del derecho de acceso.}

En el Derecho comparado el derecho de acceso se refiere mayoritariamente al concepto acuñado por la archivística de "documento". Es así, entre otros, en el propio Convenio 205. La noción de documento es amplísima, extendiéndose a todo contenido cualquiera que sea su soporte. Otra opción regulatoria, minoritaria, es la que hace pivotar el sistema sobre el concepto de "información". Ambas tienen sus pros y sus contras. En el primer caso, en un mundo caracterizado por la digitalización en bases de datos, el concepto de "documento" ha debido ampliarse para comprender los documentos que pueden elaborarse (aunque no "existan" previamente como tales) a partir de la información en ellas contenida. El tema más debatido actualmente es si debe prevalecer la decisión política sobre el grado idóneo de transparencia, de modo que la propia aplicación debería adaptarse, de ser necesario, cuando la reiteración de solicitudes de acceso vengan a poner de manifiesto el interés público 
en conocer determinado tipo de información no extraíble con las herramientas existentes del sistema ${ }^{42}$. Es un caso claro de debate sobre si el code debe condicionar el alcance del derecho, o si por el contrario debe adaptarse a las exigencias de este, por utilizar la imagen de L. LESSIG. Optar por el concepto de "información" obliga a un movimiento a la inversa, de acotamiento, para excluir un derecho a la redacción de documentos "a la carta".

El Proyecto en su redacción inicial optó por el concepto "información", que en su segunda redacción se define como "los contenidos o documentos" que obren en poder de los sujetos obligados y hayan sido elaborados o adquiridos en el ejercicio de sus funciones públicas. Puede verse en esto una respuesta a las inquietudes planteadas por el colectivo de archiveros de la función pública, acostumbrados a la noción acuñada en la archivística de documento ${ }^{43}$, definido en algunas leyes de archivo, que argumentaban además que la desaparición de esta noción en el primer Anteproyecto podría utilizarse como un apoyo para privar al solicitante del acceso al documento mismo o a una copia del mismo (a mi juicio, se trataba de un temor infundado, al menos jurídicamente, por cuanto se establece un derecho a elegir la modalidad de acceso, pero nada se pierde explicitándolo).

Claro está, el Proyecto ha tenido que establecer alguna cortapisa ante la posibilidad de solicitudes genéricas que conviertan a los sujetos obligados en auténticos "consultores" al servicio de cualquier solicitante, y al respecto establece que se exceptúan del derecho de acceso la información para cuya divulgación "sea necesaria una accesión previa de reelaboración", concepto éste cuya interpretación más o menos amplia va a ser uno de los elementos nucleares de la aplicación de la Ley. Además, se excluyen las solicitudes que se refieran a in-

42 Así, por ejemplo, en el Derecho comunitario, la práctica ha consistido en considerar como documento cualquier informe extraído de estos sistemas, que corresponda a su explotación normal. La propuesta de reforma del Reglamento 1049/2001, actualmente en curso, aclara que el derecho abarca el acceso a documentos que pueden confeccionarse a partir de bases de datos (e incluyen en el caso de la del Parlamento, de forma expresa, el "dato o contenido" en la propia definición de "documento"). La cuestión ahora radica en determinar hasta dónde llega el derecho: si a la información que pueda extraerse de la base de datos utilizando cualquier herramienta efectivamente disponible para la explotación del sistema (propuesta de la Comisión) o si dichas herramientas deben de hecho existir con una amplitud suficiente para atender a los posibles solicitudes de información (propuesta del Parlamento).

43 "Comentarios al borrador del Anteproyecto de Ley de Transparencia, Acceso a la Información Pública y Buen Gobierno" de la Asociación de Archiveros Españoles de la Función Pública. Pueden consultarse en http://www.aefp.org.es/NS/Documentos/AEFP_Comentarios_Borrador_Anteproyecto_Ley_Transparencia_AIP_BG.pdf 
formación que esté en curso de elaboración o de publicación general y la que tenga carácter auxiliar o de apoyo "como la contenida en notas, borradores, opiniones, resúmenes, comunicaciones e informes internos o entre órganos o entidades administrativas" (se ha sugerido - entre ellos yo mismo- la supresión de esta lista ejemplificativa de los "informes internos" que pudiera dar lugar a una interpretación poco favorable a la transparencia).

\section{El titular del derecho.}

En línea con la tendencia casi unánime en el Derecho comparado, y contemplada en el Convenio 205, el Proyecto reconoce el derecho a "todas las personas" (y ello pese a que el artículo 105.b habla de los "ciudadanos"): físicas o jurídicas, españolas o extranjeras, públicas o privadas. No se exige acreditar interés o consignar interés alguno -lo que refleja el fundamento del derecho como medio de fomentar la participación ciudadana y el control del poder público, y no como instrumento para la tutela de derechos o intereses individuales y a su universalización, que llevan incluso a la admisión en no pocas normas en Derecho comparado, pero no en el Proyecto, de las solicitudes anónimas-. En realidad, ambas características son realidades inescindibles. En efecto, la no exigencia de motivación entronca con la propia naturaleza del derecho y de la idea de transparencia y control democrático, y ello priva de sentido a un requisito de nacionalidad o residencia que puede - donde se exige- orillarse sin esfuerzo alguno, y virtualmente ficticio en los casos de publicidad activa.

\section{Limitaciones.}

En el Derecho comparado y en el Convenio 205 se establece una lista cerrada de excepciones, de aplicación restrictiva, que son en gran medida comunes a todos los sistemas, como comunes son las necesidades de compatibilizar transparencia y protección de intereses públicos y privados. Son en unos casos absolutas (impiden el acceso si puede poner en perjuicio determinados bienes o derechos) y en otros relativas (llaman también en esos casos a una ponderación entre esos bienes o derechos y el interés público en la divulgación de la información). El Convenio 205 y su Memoria explicativa disponen que la evaluación de riesgos puede llevarse a cabo caso por caso o bien de forma abstracta por el legislador, distinguiendo casos en los que el acceso se excluye incondicionalmente -que deben reducirse al mínimo- y otros en que hay que ponderar con el interés público en la transparencia. Además, los Estados pueden limitar temporalmente la aplicación de dichas excepciones. 
El artículo 11 establece los límites al derecho de acceso, que suponen prácticamente una traducción de los posibles límites máximos previsto en el Convenio del Consejo de Europa. Son los siguientes: la seguridad nacional, la defensa, las relaciones exteriores, la seguridad pública, la prevención, investigación y sanción de los ilícitos penales, administrativos o disciplinarios (todos ellos excluidos tanto en el primer como el segundo Anteproyecto del propio concepto de "información pública" lo que fue objeto de crítica generalizada en la consulta, por los expertos y por el Consejo de Estado y se ha modificado en el Proyecto), la igualdad de las partes en los procesos judiciales y la tutela judicial efectiva, las funciones administrativas de vigilancia, inspección y control, los intereses económicos y comerciales, la política económica y monetaria, el secreto profesional y la propiedad intelectual e industrial (éste no expresamente contemplado en el Convenio, aunque sí en diversas legislaciones nacionales, y que puede relacionarse con la protección de los intereses económicos o de la intimidad, según los casos), la garantía de la confidencialidad o el secreto requerido en procesos de toma de decisión y la protección del medio ambiente. Son límites genéricos, que por serlo han sido objeto de alguna crítica, incluso del Consejo de Estado, que no comparto, pues es lo común en el Derecho comparado ante la imposibilidad e inconveniencia de intentar encerrar una realidad absolutamente plural en fórmulas más detalladas. Por lo demás, la procedencia de alguno de ellos es discutible (como el relativo a la política monetaria, una vez comunitarizada la moneda).

La aplicación de estos límites se contempla en términos de facultad discrecional ("el derecho de acceso podrá ser restringido"), sometida al test del perjuicio ("cuando la divulgación de la información suponga un perjuicio para") y está sometida a un principio de proporcionalidad, que implica un principio de maximización del derecho que llega a que las restricciones tengan el mínimo alcance necesario ("la aplicación del los límites será justificada y proporcionada a su objeto y finalidad de la protección”), lo que conecta con el principio de acceso parcial, conforme al cual en los casos en que la aplicación de alguno de los límites no afecte a la totalidad de la información se concederá el acceso parcial previa omisión de la información afectada por el límite salvo que de ello resulte una información distorsionada o que carezca de sentido.

Además, en el segundo Anteproyecto se introdujo una última coletilla, presente en otros derechos, conforme a la cual la aplicación de los límites "atenderá a las circunstancias del caso concreto, especialmente a la concurrencia de un interés público o privado superior que justifique el acceso"). La posibilidad de que incluso cuando su divulgación puede conllevar un perjuicio para los intereses antes reseñados pueda prevalecer el interés público superior en la di- 
vulgación está contemplada en el Convenio del Consejo de Europa (y apuntalada en su Memoria explicativa, núm. 37) y en múltiples legislaciones. Sin embargo la previsión de la posible prevalencia de un interés privado superior supone un grave desconocimiento del fundamento del derecho de acceso, que no es un derecho instrumental al servicio de la protección de otros derechos, sino un derecho autónomo al servicio de la transparencia, la participación y el control de la actuación pública, conectado con el Estado democrático y, por ende, al margen de cualquier distinción en función de la motivación que pueda tener el solicitante (que, por ello mismo, ni siquiera se exige). Dicho de otro modo, el único parámetro con el que confrontar la protección de los límites es el valor que para la sociedad tiene el conocimiento de la información, un juicio abstracto desvinculado por completo de la cualidad y motivación del solicitante. Lo que, por lo demás, hace que una vez concedido el acceso, la información pueda circular libremente en la sociedad y ser conocida por cualquiera (de hecho, diversos sistemas prevén la publicación automática de la información una vez entregada a uno o varios solicitantes). La previsión, pues, que perturba de forma grave el entero sistema y debiera eliminarse.

Por lo demás, el Proyecto no establece límites temporales absolutos a la vigencia de las limitaciones. En este punto, en el Derecho comparado unas leyes lo hacen y otras no, y el Convenio del Consejo de Europa, por ello, lo prevé como una mera posibilidad de los Estados. A mi juicio, resulta más flexible el principio general según el cual las limitaciones sólo rigen cuando en efecto la divulgación pueda provocar un perjuicio para los intereses protegidos, posibilidad que a menudo el paso del tiempo contribuye a minimizar o eliminar.

\section{En particular, las relaciones entre transparencia y acceso a la información y protección de datos personales.}

El Proyecto dedica un precepto entero, el 12, un tema crucial al que he dedicado especial atención en diversos trabajos ${ }^{44}$, las relaciones entre transparencia y protección de datos, en que los principios generales que se extraen del Derecho comparado son los siguientes: preferencia de la normativa sobre transparencia y acceso cuando el solicitante es distinto del sujeto afectado, prevalencia de la privacidad cuando están en juego datos íntimos y de la publicidad cuando se trate

\footnotetext{
${ }^{44}$ Por todos, desde una perspectiva general, véase Publicidad y privacidad de la información administrativa, Civitas, Madrid, 2009; y "Transparencia versus protección de datos" en BLASCO ESTEVE, A. (coord.), El Derecho público de la crisis económica. Transparencia y sector público. Hacia un nuevo Derecho administrativo, INAP, Madrid, 2012, pp. 283-387
} 
de datos relacionados con la organización, el funcionamiento o los gastos públi$\cos$ (donde, por cierto, habría que entender incluidas las agendas de los altos cargos), todo ello salvo casos excepcionales, en los que prevalezca la protección de datos porque esté al servicio de valores superiores (como la propia integridad de las personas, en casos como el que comentamos en materia de publicidad activa en relación con los funcionarios de prisiones). Es más, buena parte de esta información ya es pública porque así lo disponen leyes sobre empleados públicos, contratación, subvenciones, régimen jurídico de las Administraciones Públicas - con el derecho a identificar a los funcionarios que tramitan un procedimiento, etc.- y, como vimos se someten ahora la obligación de publicidad activa. En los demás supuestos, debería procederse a una ponderación entre los derechos en juego y el valor de la información para la transparencia de la actividad pública. Además, es necesario establecer normas de procedimiento que permitan ponderar correctamente los intereses en juego en casos límite (dando audiencia a los afectados, sin por ello otorgarles un derecho de veto, y no facilitando la información hasta tanto la decisión sea firme). El primer y el segundo Anteproyecto se hacían eco de todos estos principios, en línea con el Derecho comparado. El único matiz es que se preveía que en los demás casos se otorgaría el acceso si tras una ponderación suficientemente razonada el órgano competente para resolver consideraba que no se perjudicaría con ello ningún derecho constitucionalmente protegido (siendo así que me parece debería más bien llamarse a una ponderación entre los derechos en juego y la transparencia, en la medida en que el derecho a la protección de datos es en sí un derecho autónomo constitucionalmente protegido, y no sólo un derecho un derecho instrumental, como reiteradamente ha puesto de manifiesto el Tribunal Constitucional, en especial en la sentencia 292/2000, por lo que se incurría en una contradicción lógico-jurídica).

Pues bien, éste ha sido, con mucho, el precepto que ha sufrido una mayor transformación, entre el segundo Anteproyecto y el Proyecto enviado a las Cortes. Y dicha transformación ha sido consecuencia de la asunción prácticamente in totum y acrítica del informe de la Agencia Española de Protección de Datos, que incluso finaliza con una redacción alternativa del precepto que ha sido copiada en el Proyecto. Dicho informe, en realidad, aprovecha materiales de diversos informes anteriores, con el grave defecto de que se proyectaban sobre realidades particulares o, directamente, diversas, como fue el informe emitido el 25 de octubre de 2011 al que sería el RDA de 18 de noviembre de 2011 al que antes nos referimos, pensado en realidad en la lógica del acceso a documentos en archivos históricos por razones culturales, y no en el acceso a información "viva" para el conocimiento y control de la gestión pública. En su informe, la AEPD peopone una mayor armonización de ambos bloques normativos, con resultados desiguales. En efecto: 
- Se mantiene en el párrafo primero la previsión de que la norma aplicable con carácter general para resolver las solicitudes es la normativa sobre acceso (la AEPD pretendía que se añadiera que también la Ley Orgánica 15/1999, de 13 de diciembre, LOPD, pero no se ha incorporado, a mi juicio correctamente, pues la mención oscurecía el sentido de la previsión), salvo cuando la información solicitada contenga sólo datos referidos al solicitante, en cuyo caso estará ejerciendo el también llamado "derecho de acceso" de la normativa sobre protección de datos y se aplicará este bloque normativo, si bien se ha añadido que ello "sin perjuicio de que, en este caso, el otorgamiento del acceso permita el conocimiento por el solicitante no sólo de los datos que contenga la información de los que sea titular, sino de esta en su totalidad" 45 . Lo cierto es que lo que pretendía esta previsión era simplemente aclarar algo ya asentado en el Derecho comparado, pero que inicialmente generó controversias en diversos países: que las solicitudes de acceso a la información se tramitan y resuelven conforme a lo dispuesto en el Proyecto, sin perjuicio del también llamado "derecho de acceso" del titular a sus propios datos que, integrante de los llamados derechos "ARCO" (acceso, rectificación, cancelación y oposición) establece en el artículo 15 de la (LOPD). Este derecho se puede ejercitar tanto frente a responsables de ficheros públicos como privados, y se refiere a la información de los datos sometidos tratamiento, su origen y las comunicaciones realizadas o que se prevén hacer de los mismos, con una regulación del plazo para otorgarlo y la prohibición, de ejercitarlo por intervalos inferiores a doce meses salvo que se justifique un interés legítimo. Este también llamado derecho de acceso se desarrolla en los artículos 27 a 30 del Reglamento de desarrollo de la LOPD y su denegación es impugnable ante la correspondiente Agencia de Protección de Datos. El artículo 27.3 prevé expresamente que "El derecho de acceso es independiente del que otorgan a los afectados las leyes especiales y en particular la Ley 30/1992, de 26 de noviembre, de Régimen Jurídico de las Administraciones Públicas y del Procedimiento Administrativo Común". No precisa si se refiere al derecho del 35.a) ("a conocer, en cualquier momento, el estado de la tramitación de los procedimientos en los que se tengan la condición de interesados, y obtener copias de documentos contenidos en ellos") o del 35.h) ("al acceso a los registros y archivos de las Administraciones Públicas en los térmios previstos en la constitución y en ésta u otras leyes", desarrollado hasta hoy en el artículo 37 de dicha Ley y en el futuro en el Proyecto que ahora estudiamos.

${ }^{45}$ En realidad la AEDPD propuso que se permitiera no sólo el conocimiento de los datos contenidos en el documento (que, junto a las cesiones que se hayan hecho de ellos, es lo que prevé la LOPD), sino del documento mismo en que aquéllos conste, para que esta previsión no pusiera al propio titular de los datos en una posición inferior al de cualquier solicitante de acceso a la información, y el redactor del Proyecto lo ha traducido en clave de "información" en lugar de "documento". 
Lo cierto es que la redacción final podría mejorarse para aclararse el principio, simple, que pretende establecerse, de aplicabilidad a las solicitudes de información de este género de la normativa sobre acceso a la información incluso si se trata de una solicitud formulada por una persona que pudiera aparecer citada en dicha información.

- En el apartado segundo se ha introducido una matización, distinguiendo dentro de los datos especialmente protegidos los del artículo 7.2 LOPD (ideología, afiliación sindical, religión y creencias), cuyo acceso por terceros sólo cabe con el consentimiento expreso y por escrito del afectado, salvo que previamente los haya hecho manifiestamente públicos; y los del artículo 7.3 LOPD (origen racial, salud y vida sexual) o datos relativos a infracciones penales o administrativas que no conllevan amonestación pública al infractor, en cuyo caso el acceso sólo se podrá autorizar en caso de que se cuente con el consentimiento expreso del afectado o si estuviera amparado por una norma con rango de Ley.

- En el caso de los documentos que contengan datos "meramente identificativos" relacionados con la organización, funcionamiento o actividad pública del órgano, con carácter general se concederá el acceso a la información, salvo que en el caso concreto prevalezca la protección de datos personales u otros derechos constitucionalmente protegidos sobre el interés público en la divulgación ${ }^{46}$. Aquí la única adición es la mención a los datos "meramente identificativos", que puede complicar el entendimiento del precepto. La AEPD intenta una interpretación integradora de los bloques normativos de protección de datos y acceso a la información, siendo así que en materia de protección de datos, el Reglamento de desarrollo de la LOPD (por cierto, extralimitándose e invadiendo la reserva de ley), en línea con la interpretación de la propia AEPD y por su iniciativa, excluyó en su artículo 2.2 del concepto de dato personal los meramente identificativo de las personas físicas en cuanto trabajadores (nombres, apellidos, funciones, dirección, teléfono...) y los datos de empresarios individuales en su condición de tales. Pero el sentido de la transparencia es más amplio, y el de este precepto (inspirado en una regla general en el Derecho comparado) es precisamente que la presencia del nombre de una persona no puede impedir que se conozcan datos relevantes sobre la actuación pública: no sólo identificativos de funcionarios o autoridades, sino relativos a las decisiones

${ }^{46}$ En este punto el Consejo de Estado sugería modificar la referencia al interés público por otra al "interés legítimo en el acceso", lo que supone un entendimiento erróneo de la naturaleza del derecho de acceso. 
públicas que adoptan que, a su vez, a menudo implica la mención de nombres de terceras personas (contratistas, beneficiarios de subvenciones, de licencias...).

- Fuera de estos casos, se mantiene una correcta regla de ponderación del interés público en la divulgación y los derechos de los afectados, en particular su derecho a la protección de datos (en realidad, debería ser sólo éste, pues los demás ya están cubiertos por otras excepciones). La novedad es que la AEPD ha querido, con "buena voluntad" rellenar la ley con criterios ponderativos, lo cual resulta encomiable si son atinados, pero puede llegar a desmontar el sistema legal, si son erróneos. Y para ello se ha valido de criterios "por arrastre" derivados de informes previos. Veamos:

Por una parte, criterios extraídos de su análisis de 2011 de la normativa sobre patrimonio histórico y archivos. Así, el menor perjuicio de los afectados derivados del transcurso de los plazos establecidos en el artículo 57 de la Ley 16/1985, de 25 de junio, del Patrimonio Histórico Español. Dicho artículo, como vimos, rige a día de hoy el acceso a los archivos que no tengan la consideración de archivos de gestión, y, si el Proyecto se mantiene en sus términos, se mantiene vigente $y$ excluye la aplicación para el resto de archivos de la normativa sobre acceso a la información que se pretende aprobar. Por ello mismo, parece inoportuna esta remisión, por lo demás compleja ${ }^{47}$. Menos justificado aún y más grave en lo que supone de torpedo a la línea de flotación del derecho de acceso como derecho autónomo vinculado a la ciudadanía y la igualdad de todos en el conocimiento de la información pública es el segundo criterio previsto, conforme al

\footnotetext{
${ }^{47} \mathrm{El}$ artículo 57 prevé que los documentos que contengan datos personales de carácter policial, procesal, clínico o de cualquier otra índole que puedan afectar a la seguridad de las personas, a su honor, a la intimidad de su vida privada y familiar y a su propia imagen, no podrán ser públicamente consultados sin que medie consentimiento expreso de los afectados o hasta que haya transcurrido un plazo de veinticinco años desde su muerte, si su fecha es conocida, o, en otro caso, de cincuenta años, a partir de la fecha de los documentos. Esta disposición ha sido un auténtico enigma en cómo interpretarla y articularla y el RDA de 2011 ha intentado "aclararla" disponiendo que si el dato del fallecimiento no consta, el interesado debe aportar certificación expedida por el Registro Civil, y que si no es posible conocer la fecha o el hecho del fallecimiento y el documento tiene una antigüedad superior a cincuenta años "el acceso se concederá si, atendidas las circunstancias del caso, se entiende razonablemente excluida la posibilidad de lesión del derecho a la intimidad personal y familiar o el riesgo para la seguridad del afectado y siempre de conformidad con la normativa sobre protección de datos" (art. 28.3), a la vez que dispone que si se trata de documentos nominativos o meramente identificativos que no afectan a la seguridad o la intimidad, es posible acceder cuando el titular haya fallecido o el solicitante acredite la existencia de un interés legítimo en el acceso, que se entenderá existente en quienes lo soliciten para el ejercicio de sus derechos y los investigadores que acrediten que el acceso se produce para una finalidad histórica, científica o estadística (art. 28.3).
} 
cual se tomará en consideración "la justificación por los solicitantes de su petición en el ejercicio de un derecho o el hecho de que tengan la consideración de investigadores y motiven el acceso en fines históricos, científicos o estadísticos". Como antes dijimos, ello supone un desconocimiento grave del sentido del derecho e introduce principios de diferencia de trato en función de la cualidad del solicitante y de justificación de intereses particulares (culturales, siendo así que, además, el Proyecto no se aplica a archivos que no sean de oficina o gestión...) ajenos a la lógica del derecho y del resto del articulado del Proyecto $^{48}$. Sería muy importante suprimir esta previsión.

Por otra, el tercer y cuarto criterios se refieren al "menor perjuicio de los derechos de los afectados en caso de que los documentos únicamente contuvieses datos de carácter meramente identificativos de aquéllos" y a "la mayor garantía de los derechos de los afectados en caso de que los datos contenidos en el documento puedan afectar a su intimidad o seguridad". Ambos son en realidad redundantes con los principios generales, y en esta medida casi superfluos, sólo que ahora se expresan en terminología propia de las leyes de acceso y no en la de protección de datos. Puesto que no hay una identificación plena, sino sólo tendencial, entre datos especialmente protegidos y datos íntimos, bien podrían, no obstante, mantenerse si contribuyen a aclarar los criterios de ponderación.

Se ha aclarado también que no es necesaria esta ponderación si el acceso se efectúa previa disociación de los datos de carácter personal de modo que se impida la identificación de las personas afectadas. En realidad, es tautológico, en la medida en que en ese caso dejan de ser datos personales ("referidos a perso-

\footnotetext{
48 Así por ejemplo, en la jurisprudencia de un país señero en la materia, como los Estados Unidos, el Tribunal Supremo ha aclarado que debe identificarse si en efecto la divulgación sería una amenaza para la privacidad, pues de lo contrario no es necesario proseguir el análisis y la información debe ser divulgada. A continuación, ha de analizarse si concurre un interés público en el conocimiento de la información, pues en caso negativo, el acceso debe denegarse. Si constata el posible perjuicio para la privacidad y el interés público de la información, el Tribunal Supremo ha sentado el principio según el cual la apreciación del interés público contrapuesto a la privacidad ha de hacerse en términos objetivos, esto es, en función de la naturaleza de la información y su idoneidad para contribuir a la transparencia y control de la actuación administrativa. Por tanto, el interés personal del solicitante es irrelevante, lo que implica que la Administración debe tratar de igual modo a cualquier solicitante respecto de la misma información (salvo aquella en que el solicitante sea el propio afectado). Es más, ha de hacerse abstracción de la finalidad particular del solicitante, y focalizar en la naturaleza del documento solicitado y su relación con el interés público general, y los posibles efectos de la divulgación en el público en general. Se excluye, por tanto, la información solicitada para obtener o complementar pruebas para un proceso judicial privado, para cuyo acceso han de utilizarse los cauces oportunos dentro del proceso judicial. Esta perspectiva tiene además como consecuencia la de facilitar un criterio que permite también su aplicación a categorías abstractas de documentos. El leading case lo constituye la sentencia de 1989 dictada en el asunto United States Department of Justice v. Reporters Committee for Freedom of the Press [489 U.S. 749 (1989)].
} 
nas identificadas o identificables"), pero si contribuye a orientar a los aplicadores de la norma hacia esta modalidad de acceso parcial, conocida de muchas normas sobre acceso en el Derecho comparado, puede ser bien recibido. En efecto, en muchas ocasiones, basta la disociación para conseguir un correcto equilibrio entre transparencia y protección de datos ${ }^{49}$.

Finalmente, se han mantenido la previsión de que la normativa sobre protección de datos personales es de aplicación al tratamiento posterior de los obtenidos a través del ejercicio del derecho de acceso, que, aunque sea innecesaria, contribuye a reforzar la integración de ambos bloques normativos ${ }^{50}$.

\section{Procedimiento y organización.}

El Derecho comparado pone de relieve la necesidad de diseñar un procedimiento simple, ágil y económicamente asequible para todos los ciudadanos, pues está en juego precisamente su participación efectiva en la vida democrática y la información requiere para ser útil inmediatez.

El Proyecto, estimo, regula de forma muy convincente el procedimiento. Establece libertad de medios para la solicitud, bastando con que conste la identidad, la información que se solicita, una dirección de contacto a efecto de comunicaciones, preferentemente electrónica, y en su caso la modalidad de acceso que se prefiera. Las solicitudes no requieren motivación, que es meramente opcional. He defendido en otros trabajos que se trata de una previsión sana, la de permitir expresar los motivos, para una mejor ponderación del interés para el público que puede tener la información. En esa medida, la solución me parece acertada, si bien no su formulación ("el solicitante podrá incluir los motivos por los que solicita la información y que deberán ser tenidos en cuenta cuando se dicte resolución”), ya que, como vimos, si algo deja claro el Derecho comparado es que los motivos que cada persona pueda tener para so-

\footnotetext{
${ }^{49}$ Por ejemplo, con carácter general, para controlar la correcta evaluación de pruebas de oposición, y con ello, la vigencia del acceso por mérito y capacidad, basta comparar el contenido de varios que hayan exámenes que hayan obtenido la misma calificación, sin necesidad de conocer la concreta identidad de las personas que los hayan realizado.

${ }^{50}$ Además se ha añadido, a sugerencia de la AEPD, una disposición adicional quinta sobre colaboración con la AEPD, que prevé que ésta y ATEVAL adopten conjuntamente las resoluciones que sean necesarias a fin de determinar los criterios de aplicación de estas reglas, en particular en lo que respecta a la ponderación del interés público en el acceso a la información y la garantía de los derechos de los interesados cuyos datos se contuviesen en la misma, de conformidad con lo dispuesto en esta norma y en la LOPD.
} 
licitar información no han de ser tenidos en absoluto en cuenta para la decisión, que es un juicio abstracto, desvinculado de la identidad del solicitante, que deben ponderar los derechos o bienes afectados con el interés público de la generalidad de los ciudadanos en la divulgación de la información. La redacción acogida por el Proyecto es, cuanto menos, ambigua, y podría ser susceptible de una interpretación referida a los motivos personales de cada solicitante que desenfocara el entero edificio de la transparencia.

Acoge causas de inadmisión, mediante resolución motivada, que incluyen la información que no obra en poder del órgano al que solicita cuando se desconozca el competente (pues, de conocerse, debe reenviársele la solicitud; sin embargo, el 15.2 dispone que en el caso de que se inadmita una solicitud por esta causa, el órgano que acuerde la inadmisión debe indicar en la resolución el órgano que, a su juicio, es competente para conocer de la solicitud, lo que parece un contrasentido); o las manifiestamente repetitivas o abusivas (algo común en muchas normas de otros países). Ahora bien, también incluye la relativa a información exceptuada del derecho de acceso (con la crítica que antes formulé) y la que afecte a una pluralidad de personas cuyos datos personales pudieran revelarse con el acceso a la petición, en número tal que no sea posible darles traslado de la solicitud en el tiempo establecido para su resolución, caso éste en el que lo procedente sería más bien que resolviera el órgano competente ponderando en abstracto sin audiencia de los afectados (que por lo demás, como dije, carecen de derecho de veto).

La tramitación es ágil y pro actione, reenviando la solicitud al órgano que posee la información cuando se conoce o cuando haya sido elaborada o generada en su integridad o parte principal por otro, y solicitando precisiones en casos de solicitudes demasiado imprecisas y con un plazo para que los terceros afectados formulen alegaciones (no sólo puede estar en juego la protección de datos, sino la propiedad industrial, el secreto comercial, etc.). El plazo de resolución se mueve dentro de parámetros comparados razonables: de un mes desde la recepción, ampliable por otro mes en el caso de que el volumen o la complejidad de la información que se solicita así lo hagan necesario, previa notificación al solicitante, añadido propuesto por el Consejo de Estado. Han de ser motivadas las resoluciones que denieguen el acceso, las que concedan el acceso parcial o a través de una modalidad distinta a la solicitada y las que permitan el acceso cuando haya habido oposición de un tercero. Las resoluciones deben notificarse al solicitante y a los terceros afectados que así lo hayan solicitado (parece un tanto restrictivo exigir una petición expresa de un tercero que no tiene por qué conocer esta exigencia, por lo que debería en ese caso preverse que se le informe de esta posibilidad). 
Especial atención merece el tema del silencio, que se prevé como negativo, lo que ha sido objeto de numerosas críticas, en particular, por organizaciones no gubernamentales y medios de comunicación. Críticas a mi juicio absolutamente injustificadas. Me atrevo a afirmar que en esta materia sólo cabe razonablemente esta solución (al menos si queremos seguir teniendo Estado y derechos constitucionales). No parece casual que sea la acogida por la práctica generalidad de leyes de acceso a la información en el Derecho comparado. ¿Acaso la sociedad estaría dispuesta a que por el mero transcurso del plazo para recurrir hubiera que desvelar planes de lucha contra el narcotráfico o el historial clínico de cualquier ciudadano? El tema no merecería detenerse en él si no fuera, como digo, por las críticas recibidas, que desconocen que el silencio no es una opción, sino una garantía frente al incumplimiento de una obligación, o la propia naturaleza del silencio positivo como auténtico acto declarativo de derechos que, en caso de no hacerse efectivos, cabe reclamar judicialmente sin que el tribunal pueda entrar en el fondo del asunto. Como medida pedagógica y de "fomento" del cumplimiento, sugerí en la comisión de expertos una mención específica a las sanciones disciplinarias ante incumplimientos reiterados, que ha sido acogida como infracción grave a los efectos de la aplicación a sus responsables del régimen disciplinario previsto en la correspondiente normativa reguladora.

En caso de concederse el acceso, se opta por la modalidad electrónica salvo petición en contrario, lo que me parece razonable siempre, claro, que se haya consignado una dirección electrónica en la solicitud. Cuando la información ya ha sido publicada, basta como indicar al solicitante cómo puede acceder a ella (podría añadirse, siempre que esté razonablemente disponible, como hacen algunas normas de otros países). El acceso es gratuito, si bien la expedición de copias o la transposición de la información a un formato diferente al original pueden dar lugar a la exigencia de exacciones. Un problema que no podemos abordar aquí, pero de gran interés, es la no evidente articulación de esta ley con la normativa estatal sobre reutilización de la información pública con fines comerciales, regulada en una Directiva comunitaria, ahora en revisión, y adaptada en España por la Ley 37/2007, de 16 de noviembre.

Para hacer efectiva la gestión de la información conforme a este procedimiento, el Proyecto obliga a todas las Administraciones Públicas incluidas en su ámbito de aplicación a establecer sistemas para integrar la gestión de solicitudes de información de los ciudadanos en el funcionamiento de su organización interna. Se trata de un principio muy general acorde con la naturaleza básica de la norma y la competencia de cada Administración para autoorganizarse, introducido de hecho en el segundo Anteproyecto. Para la AGE, se pre- 
vé la creación de Unidades especializadas de Información, competentes para recabar y difundir la información sometida a publicad activa, recibir y dar tramitación a las solicitudes de acceso a la información, realizar los trámites internos necesarios para dar acceso a la información solicitada, realizar el seguimiento y control de la correcta tramitación de las solicitudes de acceso a la información; llevar un registro de las solicitudes de acceso a la información; asegurar la disponibilidad en la respectiva página web o sede electrónica de la información cuyo acceso se solicita con más frecuencia; mantener actualizado un mapa de contenidos en el que queden identificados los distintos tipos de información que obre en poder del órgano (estas dos últimas introducidas en la segunda redacción) así como todas aquellas funciones que sean necesarias para asegurar una correcta aplicación de las disposiciones de esta Ley. Aunque el Proyecto no incardina estas Unidades de Información en ningún órgano concreto, parece que, habida cuenta sus competencias generales en materia de información y coordinación, las Subsecretarías están llamadas a integrar a dichas Unidades. El resto de entidades son libres para establecer su organización, siempre que identifiquen claramente el órgano competente para conocer de las solicitudes de acceso. Junto a las unidades especializadas, cabe reseñar que el Derecho comparado conoce otras técnicas organizativas, formativas y de difusión al servicio de la efectividad del Derecho, incluidas la edición de guías ciudadanos que acerquen de forma pedagógica y con un lenguaje llano el contenido del derecho al ciudadano medio o la llevanza y publicidad electrónica de registros de documentos que permitan búsquedas con criterios sencillos.

\section{Garantías.}

Las resoluciones en materia de acceso ponen fin a la vía administrativa y son recurribles ante la jurisdicción contencioso-administrativa. Se trata de una importante novedad incorporada en el segundo Anteproyecto, que sugerí en el comité de expertos, pues la primera redacción remitía al régimen general de los recursos administrativos, y, por ende, a la necesidad de interponer recurso de alzada si se trataba de decisiones que no agotaban la vía administrativa, lo que podía suponer, por una parte, una dilación mal avenida con la necesidad de respuesta rápida que caracteriza el mundo informacional (conocer para participar y controlar) y, por otra, el riesgo de que, en caso de silencio en vía recurso de alzada frente a un silencio en vía de solicitud se produjera el silencio positivo previsto en el artículo 43.1 LRJAP-PAC, indeseable por las razones obvias antes enunciadas. Habría que eliminar, sin embargo, la referencia a la "vía administrativa", que habida cuenta que en algunas ocasiones no está en juego por tratarse de sujetos obligados que no tienen esa naturaleza, es técni- 
camente defectuosa (o bien añadir un "en su caso"). En esta línea, obsérvese que se unifica la competencia en la jurisdicción contencioso-administrativa (siendo así que algunas decisiones pueden provenir de sujetos privados, como las sociedades mercantiles de capital mayoritario público) lo que me parece acertado y coherente con la noción funcional que se va imponiendo en el Derecho administrativo, si bien plantea si no sería conveniente aclarar esta cuestión también en el artículo 2 de la Ley de la Jurisdicción Contencioso Administrativa y evitar así posibles conflictos con el orden jurisdiccional civil. Se prevé por lo demás, acertadamente, que si ha existido oposición de tercero el acceso sólo tendrá lugar cuando, habiéndose concedido dicho acceso, haya transcurrido el plazo para interponer recurso contencioso administrativo sin que se haya formalizado o haya sido resuelto confirmando el derecho a recibir la información. Habría de añadirse, por sentencia firme, pues cualquier concesión de información hace que un posterior recurso contra la sentencia que reconoce el derecho pierda su objeto, al haberse divulgado ya la información.

Cabe (potestativamente) interponer una reclamación previa a la vía contencioso-administrativa ante un órgano independiente ${ }^{51}$, en el plazo de un mes a contar desde el día siguiente al de la notificación del acto impugnado o a aquel en que se produzcan los efectos del silencio (esto último choca con la doctrina constitucional que declara siempre abierto el plazo para recurrir contra desestimaciones por silencio), con audiencia de los terceros afectados. El plazo de resolución es tres meses por sugerencia del Consejo de Estado, por asimilación del plazo para la resolución de los recursos de alzada, mientras que el previsto en el primer y el segundo Anteproyectos era de un mes. Este alargamiento del plazo es difícil de juzgar; en sin duda un retroceso en la efectividad del derecho en relación con lo antes previsto, pero si resulta en realidad más realista, contribuye a que los asuntos obtengan una resolución expresa en plazo, y evita la posibilidad de frecuentes silencios por desbordamiento ante los que solo quepa acudir a los tribunales contencioso-administrativos no me parece inasumible.

Esta reclamación es sustitutiva de los recursos administrativos procedentes (que no siempre caben, como dijimos, pues no siempre se trata de decisiones administrativas) de conformidad con la posibilidad que al respecto abre el artículo 107.2 LRJAP-PAC. Esta vía es clave para la efectividad del derecho ya que la respuesta a las reclamaciones de información o es rápida y gratuita o,

${ }^{51}$ Salvo en el caso de las decisiones de los órganos constitucionales y estatutarios no administrativos mencionados en el art. 2.1.f) del Proyecto, para evitar que una Administración controle actos de este tipo de órganos. 
en buena medida, "no es". Máxime cuando, como hemos señalado, el Proyecto no ancla el derecho de acceso en la libertad de información y, por ello mismo, no implica su protección judicial por procedimiento sumario de protección de los derechos fundamentales regulado en los artículos 114 a 123 de la Ley de la Jurisdicción Contencioso-Administrativa. Se prevén mecanismos para dar audiencia a los afectados, si los hubiere.

Ahora bien, ha de advertirse que un punto débil del Proyecto es cuál sea la autoridad independiente competente en el ámbito estatal, prevista en su art. 21. En el Derecho comparado, al margen de la garantía judicial última y de la posibilidad de queja ante el Defensor del Pueblo, las normas sobre transparencia de las últimas décadas han incorporado la creación de una autoridad independiente, unas veces con competencias exclusivas en materia de acceso a la información (Francia, Portugal, Italia, por ejemplo) y otras unificadas con la materia de protección de datos (Gran Bretaña, Alemania, Suiza, por coger ejemplos cercanos). Se dan además diversas combinaciones: órganos de nombramiento parlamentario o gubernamental, unipersonales o colegiados, con poder para dictar recomendaciones o para ordenar la entrega de información. En otros trabajos he puesto de manifiesto los pros y los contras que en nuestro Derecho podrían tener ambas opciones. La unificación de competencias en la Agencia Española de Protección de Datos (AEPD), que figuraba en proyectos normativos del anterior Gobierno y que ha sido defendida por múltiples expertos y organizaciones no gubernamentales, tendría ventajas como son, fundamentalmente, la posibilidad de dar una respuesta unitaria y coherente a la publicidad de información que contiene datos personales, aparte de apoyarse sobre una Institución ya existente, sólida y con importantes poderes. Ahora bien, cuenta a mi juicio con los siguientes inconvenientes: a) la AEPD tiene un conocimiento especializado en protección de datos. Por tanto, la materia de acceso a la información pública le es ajena, salvo en lo tocante a su conexión con los datos personales. En particular, no pertenecen a su acervo de conocimientos las materias que se anudan a otro tipo de limitaciones al acceso (relaciones exteriores, seguridad pública, persecución de los delitos...); b) la AEPD ejerce sus competencias no solo respecto a entidades públicas, sino también respecto a sujetos privados, pues a ambos se le aplica la LOPD, mientras que la Ley de Transparencia y Acceso a la Información Pública tiene como obligados a sujetos públicos y solo excepcionalmente a sujetos privados cuando ejercen funciones públicas, por lo que los sujetos controlados bajo una y otra ley son diferentes; c) la AEPD tiene ya una importante carga de trabajo, pues su competencia se extiende a todos los ficheros públicos salvo los autonómicos y locales de Comunidades Autónomas que hayan creado sus propias agencias y a todos los privados, cualquiera que sea el lugar donde están ubicados, junto con competencias sobre vi- 
deovigilancia o sociedad de la información; y d) la AEPD ha nacido como institución especializada en la protección de los datos. Al extender su competencia a la información, se corre el riesgo (que se ha hecho sentir en otros sistemas) de que continúe actuando en una lógica "defensiva" y lleve a cabo por ello una interpretación restrictiva del principio de transparencia y publicidad cuando la información contiene datos personales, lo que me parece un potencial inconveniente que no conviene desdeñar. En caso de que se hubiera decidido atribuirle la competencia sobre transparencia y acceso a la información, habría, pues, que intentar combatir las mencionadas desventajas. Respecto a los dos primeros puntos, sería necesario fijar que la Agencia integrara claramente la idea de que en adelante es una entidad de transparencia y protección de datos. Se requeriría una nueva cultura que fuera acompañada de una nueva organización interna que reflejara esta dualidad y, en su caso, de un reciclaje formativo de una parte de su personal. En relación con los dos últimos aspectos, sería necesario dotar a la Agencia con un incremento de medios personales y tal vez materiales, e incidir en la formación sobre las nuevas materias. Parece claro que ello no implicaría una duplicación de costes, y que, por tanto, no quedaría anulado el objetivo de ahorro presupuestario, pero sí hay que asumir que no se puede extender la competencia de la AEPD con coste cero.

En todo caso, el Proyecto no ha mirado hacia la AEPD. Tampoco ha querido crear una nueva Institución, algo difícil de vender políticamente en estos tiempos, como se puede incluso leer entre líneas en la Exposición de Motivos ("en aras de la necesaria austeridad exigida por las actuales circunstancias económicas"; obviando por lo demás que el gasto en una Institución que haga eficaz la transparencia, siendo limitado, redunda entre otros, en una mejor gestión de los recursos públicos) sino que ha decidido atribuir su competencia a una ya existente: la Agencia Estatal ahora denominada de Transparencia, Evaluación de las Políticas Públicas y de la Calidad de los Servicios (la actual AEVAL). La opción en sí, pese a constituir una singularidad hispana, no parece del todo desenfocada, puesto que, en efecto la transparencia tiene directa relación con la evaluación de las políticas públicas y de la calidad de los servicios, si bien resulta cuestionable que esta Institución esté preparada para cumplir ambos cometidos y necesitará, en todo caso, una auténtica refundación, con incorporación de personal y con un importante esfuerzo de formación de sus recursos humanos. Lo que me parece más importante (o al menos, tanto como lo anterior) es analizar si en efecto estamos en este caso ante una auténtica Institución independiente, como exige la Ley. En principio, no cabe llegar a esa conclusión, puesto que, a diferencia de la AEPD, AEVAL no tiene la consideración de Administración independiente, sino de Agencia de las reguladas en la Ley 28/2006, de 18 de julio, de Agencias estatales para la mejora de los ser- 
vicios públicos, que la adscribe al Ministerio de Administraciones Públicas (hoy, de Hacienda y Administraciones Públicas). Su Estatuto (Real Decreto 1418/2006, de 1 de diciembre) establece, no su independencia, sino su más limitada "autonomía de gestión y funcional dentro de los límites establecidos por la Ley de Agencias Estatales y por este Estatuto", y una estructura orgánica integrada por dos órganos de gobierno: el presidente, nombrado y separado libremente por el Consejo de Ministros, a propuesta del Ministro de las Administraciones Públicas, y el Consejo Rector, órgano de gobierno colegiado de composición mayoritariamente interministerial y entre cuyas funciones están, destacadamente, el seguimiento, supervisión y control superior de la actuación de la Agencia o el nombramiento del personal directivo, que no es por tanto equivalente, ni en su composición ni en sus funciones al Consejo Consultivo de la AEPD. A mi juicio, es ésta una de las más importantes fallas del Proyecto. Ciertamente, el Proyecto modifica la regulación legal para introducir un derecho de veto de la propuesta gubernamental de nombramiento del Presidente, por mayoría absoluta de la Comisión de Administraciones Públicas del Congreso de los Diputados. Ciertamente también, a resultas de diversas críticas en la prensa y en la comisión de expertos, entre ellas las por mí formuladas ${ }^{52}$ acerca de la incompatibilidad de la libre remoción del Presidente y de la configuración interministerial de su órgano de gobierno, el segundo Anteproyecto dispone ahora causas tasadas para el cese del Presidente, alineándolo ahora con el "blindaje" del propio Director de la AEPD o de los miembros de los organismos reguladores. No obstante, nos parece que sería necesario regular también una nueva composición y funciones del llamado "Consejo Rector", que debiera pasar a ser un órgano consultivo a semejanza de lo que ocurre con la AEPD, si se mantiene la atribución de esta competencia a la actual AEVAL. A mi juicio, sería la solución menos mala dentro del esquema adoptado, pues, como he defendido en otros trabajos, la estructura más idónea, habida cuenta la necesidad de dotar a la institución de la máxima independencia, del carácter complejo y polémico de muchas cuestiones ponderativas que se suscitarán y de la importancia del poder otorgado el órgano, que puede revocar una decisión de las más altas instancias políticas, sería en el ámbito estatal una institución colegiada de nombramiento parlamentario de acceso a la información.

Predicar con el ejemplo es en este caso tanto más importante por cuanto el Proyecto impone la solución de la existencia de un órgano independiente respecto de todas las Administraciones, no sólo de la estatal, entendimiento éste que, me parece, explica la apelación al $149 \cdot 1.1^{\text {a }} \mathrm{CE}$ como título competencial de refuerzo. Sigue así el modelo adoptado en materia de protección de datos,

52 "Transparencia: la hora de la verdad", en Diario ABC de 30 de abril de 2012. 
bendecido por la STC 290/2000, aunque sólo parcialmente, dado que, a diferencia de lo que ocurre en esa materia, en el caso de la transparencia y el acceso a la información la Agencia estatal es competente para conocer reclamaciones contra actuaciones fuera del ámbito de la AGE en caso de falta de creación de su propio órgano independiente sólo si se suscribe el correspondiente convenio con la AGE, en el que se estipulen las condiciones en que la Comunidad sufragará los gastos derivados de esta asunción de competencias. Por tanto, las Comunidades y Ciudades Autónomas pueden, o bien suscribir convenios, o bien están obligadas a determinar (antes del plazo de un año de vacatio legis fijado en el Proyecto) el órgano independiente competente para la resolución de las reclamaciones "en los supuestos de resoluciones dictadas por las Administraciones de las Comunidades Autónomas, sus Asambleas Legislativas y las instituciones autonómicas análogas al Consejo de Estado, Tribunal de Cuentas Defensor del Pueblo, así como en los de resoluciones dictadas por las Entidades Locales comprendidas en su ámbito territorial". Obsérvese que en el caso de las Entidades Locales, el Proyecto opta por una solución similar a la contenida en la LOPD, la de atribuir la competencia a un órgano independiente autonómico. Dicho órgano, por cierto, bien podría ser la Agencia autonómica de Protección de Datos (las existentes, Madrid, Cataluña y el País Vasco) o las que puedan crearse haciendo virtud de la necesidad de crear un órgano independiente (salvo convenio con la AGE). Y ello por cuanto la unificación de competencias estaría más claramente justificada en el caso de las agencias autonómicas, en la medida en que muchos de esas desventajas no concurren o lo hacen en menor medida ${ }^{53}$.

La cuestión es sumamente relevante desde el punto de vista de la autonomía decisional porque la competencia más importante de estos órganos independientes (al margen de la elaboración de informes anuales y otras) es la resolución de reclamaciones, que, tal y como están configuradas en el Proyecto y

${ }^{53}$ En efecto: a) en el ámbito autonómico, la protección de datos es la principal limitación a la transparencia, dado que muchas de las restantes son en principio ajenas al ámbito de competencias de las Comunidades Autónomas: b) el modelo de agencias autonómicas está aún, en gran medida, por desarrollar, pues, si bien han sido incluso previstas en la mayor parte de la nueva generación de estatutos de autonomía, la realidad es que por el momento sólo se han creado tres, la madrileña, la catalana y la vasca, por este orden temporal, todas ellas, además, más recientes que la española, por lo que es posible aún crear o adaptar (en estos tres casos) una institución que responda plenamente a esta doble lógica ponderada de la publicidad y de la privacidad; c) las Agencias autonómicas ejercen sus funciones exclusivamente sobre ficheros públicos. De este modo, y a partir de una concepción funcional del ejercicio de funciones públicas tanto en materia de acceso a la información como de protección de datos, se llega a una potencial coincidencia en el ámbito de los sujetos obligados; d) finalmente, y como consecuencias de las tres características diferenciales apuntadas, la carga de trabajo de las agencias autonómicas es inferior, por lo que podrían asumir razonablemente la competencia en materia de acceso a la información. 
aunque no se diga expresamente, ha de entenderse que tienen valor ejecutivo y obligan, pues, en su caso, a facilitar la información que haya sido erróneamente denegada. Así se deriva de su regulación, en la que aparece como sustitutiva de los recursos administrativos y como previa a la vía contencioso-administrativa y de la atribución de sentido desestimatorio al silencio, si bien el Proyecto podría haber sido más claro, como de hecho se sugirió en la consulta pública. En el ámbito estatal, se atribuye la competencia para dictarla al Presidente, un poder realmente importante en manos de una sola persona ${ }^{54}$.

\section{Coda: el margen de actuación de las Comunidades Autónomas.}

Las Comunidades Autónomas (y las entidades locales) han estado al margen del proceso de elaboración de esta norma (como apuntó, críticamente, el dictamen del Consejo de Estado) pero están llamadas a desarrollarla y aplicarla, pues sus Instituciones y sujetos vinculados a ellas figuran entre los obligados por la ley en los mismos términos que sus equivalentes de ámbito estatal.

El Proyecto de Ley ha hecho un entendimiento muy amplio de la competencia para establecer las bases del régimen jurídico de las Administraciones públicas, de modo que casi toda la regulación tiene carácter básico, incluidas las disposiciones sobre procedimiento, incluidos el plazo y el sentido del silencio. Sólo ha excluido de dicho carácter:

- La regulación del Portal de Transparencia de la AGE. No obstante, se dispone, como vimos, con carácter básico, que la información sujeta a las obligaciones de transparencia sea publicada en las correspondientes sedes electrónica y páginas web de manera clara, estructurada y entendible para los interesados, con mecanismos para facilitar la accesibilidad, la interoperabilidad, la calidad y la reutilización de la información publicada así como la identificación y localización, así como la accesibilidad para personas con discapacidades. Igualmente se prevé como básico que todas las Administraciones pueden adoptar medidas complementarias y de colaboración para el cumplimiento de las obligaciones de transparencia.

\footnotetext{
54 Se afirma de forma tangencial, al disponer que "El Presidente de la Agencia Estatal de Transparencia, Evaluación de las Políticas Públicas y de la Calidad de los Servicios comunicará al Defensor del Pueblo las resoluciones que dicte en aplicación de este artículo y elaborará anualmente una memoria en la que se analice el cumplimiento de las disposiciones contenidas en este Título".
} 
- La regulación de las Unidades de Información, si bien se prevé como básico que las Administraciones deben establecer sistemas para integrar la gestión de solicitudes de información de los ciudadanos en el funcionamiento de su organización interna e identificar claramente el órgano competente para conocer de las solicitudes de acceso.

- Finalmente, la disposición adicional cuarta prevé que la reclamación prevista en el artículo 21 ante ATEVAL, en el ámbito estatal, corresponderá, en el caso de las Administraciones autonómicas o locales, u otros sujetos a ellas vinculadas y sometidos a esta norma, al órgano independiente que determinen las respectivas normativas autonómicas (o acuerden las ciudades autónomas de Ceuta y Melilla). También pueden optar por atribuir esta competencia a ATEVAL, celebrando a tal efecto el correspondiente convenio con la AGE, en el que se estipulen las condiciones en que la Comunidad sufragará los gastos derivados de esta asunción de competencias. Esta previsión, en todo caso, de la existencia de un órgano independiente de control como garantía objetiva del derecho parece apoyarse en el título competencial del artículo 149.1.1 CE, análogamente a como sirvió en la LOPD para justificar la necesaria existencia de un órgano independiente de control, la AEPD, con competencia para el control de todos los ficheros privados y de los ficheros públicos estatales, así como, en caso de inexistencia de autoridades independientes de control autonómicas, del resto de ficheros públicos. No obstante, obsérvese, este título competencial se invoca sin que se reconozca el carácter de derecho fundamental del derecho de acceso y, por ende, en una ley toda ella ordinaria (a diferencia de lo que ocurre en el caso del derecho fundamental a la protección de datos, posibilidad que no es pacífica en la jurisprudencia constitucional.

El retraso en la aprobación de la Ley estatal sobre Transparencia y Acceso a la Información ha hecho que diversas Comunidades Autónomas hayan tomado la delantera, aprobando sus propias leyes sobre la materia. Es el caso de la Galicia (Ley 4/2006, de 30 de julio, de transparencia y buenas prácticas en la Administración pública gallega), Baleares (Ley 4/2011, de 31 de marzo, de la buena administración y del buen gobierno de las Islas Baleares) o Navarra (Ley Foral 11/2012, de 21 de junio, de Transparencia y del Gobierno Abierto). En otros casos, la iniciativa se encuentra actualmente en el Parlamento autonómico (Propuesta de Ley de Gobierno Abierto de Extremadura, formulada conjuntamente por todos los grupos parlamentarios, BOAE núm. 236 de 10 de octubre de 2012). En otros, las iniciativas se frustraron por adelantos electorales, pero se anuncia que se retomarán por el nuevo Gobierno (es el caso de País Vasco y Cataluña). Finalmente, otros Gobiernos autonómicos han anunciado su voluntad de mandar al Parlamento sus propios proyectos de Ley (es el ca- 
so de Andalucía, Canarias, Castilla y León, Aragón...). A ello se le suman iniciativas de diversos grupos parlamentarios en otras Comunidades (como en la Comunidad Valenciana), que sin duda servirán para espolear a sus Gobiernos a tomar la iniciativa.

Hay que decir que estas leyes autonómicas tienen una muy desigual amplitud en su objeto regulatorio. Las más modernas comienza a inscribirse en el concepto más amplio de Gobierno Abierto, contemplado como una nueva forma de gobernanza participativa basada en el permanente flujo de información y puntos de vista a través de canales multidireccionales entre la Administración y los ciudadanos. O bien, en esta línea y un sentido más restringido, acogen la idea del open data entendido como puesta a disposición de la sociedad de la información en poder de la Administración en formatos reutilizables para que pueda ser importada y tratada por empresas, periodistas, ONGs y ciudadanos en general, para la "puesta en valor" mediante el cruce de información, el desarrollo de aplicaciones, etc. (en directa conexión con la normativa sobre reutilización de la información pública, regulada con carácter básico en la Ley de 2007, ley que se modificará en el futuro cuando se apruebe la nueva Directiva comunitaria sobre reutilización) ${ }^{55}$.

Una vez que se apruebe es de prever la aprobación de leyes (los antecedentes que acabamos de reseñar permiten aventurarlo) e incluso la necesaria adaptación de las ya aprobadas a las bases estatales. Queda en el margen de actuación de las Comunidades Autónomas decidir la amplitud de sus Leyes (de Transparencia y Acceso a la Información, de Buen Gobierno, de Gobierno Abierto, de Reutilización y Datos Abiertos, de Participación, de todo ello o de cualquier combinación...) y hacerlo, esperemos, de forma realista y coherente con el marco básico estatal.

\footnotetext{
55 Así, convencionalmente podría decirse que la Ley gallega de 2005 es una ley de transparencia, acceso a la información y buen gobierno; que la Ley balear de 2011 es una ley de administración electrónica, transparencia, buen gobierno, evaluación y calidad de las políticas públicas; que la Ley Navarra de 2012 es una ley de gobierno abierto, que incluye la transparencia, la participación, la modernización, la racionalización, simplificación y la mejora de la calidad y el buen gobierno; que la Propuestas de Ley extremeña lo es de transparencia, acceso a la información, reutilización, buen gobierno y participación...
} 